\title{
New biomaterials for orthopedic implants
}

This article was published in the following Dove Press journal:

Orthopedic Research and Reviews

8 September 2015

Number of times this article has been viewed

\section{Kevin L Ong \\ Brian Min Yun \\ Joshua B White \\ Exponent, Inc., Philadelphia, PA, USA}

Correspondence: Kevin L Ong Exponent, Inc., 3440 Market Street, Suite 600, Philadelphia, PA 19104, USA

$\mathrm{Tel}+\mathrm{I} 2155948874$

Fax + I 2155948899

Email kong@exponent.com
Abstract: With the increasing use of orthopedic implants worldwide, there continues to be great interest in the development of novel technologies to further improve the effective clinical performance of contemporary treatment modalities and devices. Continuing research interest also exists in developing novel bulk biomaterials (eg, polycarbonate urethanes, silicon) or novel formulations of existing but less widely used biomaterials (eg, polyaryletherketones, polyetheretherketone). There is also growing focus on customizing the material properties of bioabsorbables and composite materials with fillers such as bioactive ceramics. In terms of tissue engineering, more recent developments have focused on basic engineering and biological fundamentals to use cells, signaling factors, and the scaffold material itself to better restore tissue and organ structure and function. There has also been recent controversy with the use of injectables as a nonsurgical approach to treat joint disorders, but more attention is being directed toward the development of newer formulations with different molecular weights. The industry has also continuously sought to improve coatings to supplement the function of existing implants, with the goal of improving their osseointegrative qualities and incorporating antimicrobial properties. These include the use of bone morphogenetic protein, bisphosphonates, calcium phosphate, silicon nitride, and iodine. Due to the widespread use of bone graft materials, recent developments in synthetic graft materials have explored further development of bioactive glass, ceramic materials, and porous titanium particles. This review article provides an overview of ongoing efforts in the above research areas.

Keywords: coatings, scaffolds, bioabsorbables, bone graft, injectables

\section{Introduction}

With the increasing use of orthopedic implants worldwide, there continues to be great interest in the development of novel technologies to further improve the effective clinical performance of contemporary treatment modalities and devices. The design of an orthopedic device includes aspects of the bulk material and coatings. Novel bulk biomaterials or novel formulations of existing biomaterials are being considered to improve their wear characteristics and longevity, as well as interaction with the surrounding biological environment. There is also growing focus on customizing the material properties of bioabsorbables and composite materials with fillers for nonpermanent devices. Nonpermanent devices may also include the use of cells, signaling factors, or scaffold material to better restore tissue function. Although many types of coatings, such as beaded, plasma spray, and sintered etc, are widely used on orthopedic devices, the goal of improving their osseointegrative qualities and incorporating antimicrobial properties is a continuous endeavor. In situations where bone substitutes are needed, 
improvements in synthetic graft materials are being sought. Therefore, this review provides an overview of ongoing efforts in biomaterials research for orthopedic applications, including a summary of bulk materials, tissue engineering materials, coatings, and graft materials.

\section{Bulk materials}

Contemporary materials, such as cobalt chrome, polyethylene, and ceramic (alumina, zirconia), are widely accepted as bulk biomaterials for orthopedic implants. However, there continues to be interest in developing novel biomaterials or novel formulations of existing, but less widely used, biomaterials. These materials have to take biocompatibility and their mechanical properties, such as strength, wear, and load-carrying capacity, into consideration. Bioabsorbables and their composite counterparts continue to expand in their applications, with growing focus on customizing the material properties of the bioabsorbable components. The following sections provide an overview of the ongoing development of permanent bulk biomaterials, bioabsorbables, and composite materials.

\section{Polyaryletherketones}

Polyaryletherketones (PAEKs) have been increasingly used as biomaterials for orthopedic, trauma, and spinal implants, following confirmation of their biocompatibility in the $1980 \mathrm{~s} .{ }^{1}$ PAEKs are a family of high-temperature thermoplastic polymers that contain an aromatic backbone molecular chain with interconnected ketone and ether functional groups. Growing interest in this family of polymers was originally due to the development of "isoelastic" hip stems and fracture fixation plates with stiffness properties comparable to bone. PAEK polymers are appealing in many industrial applications, including as a biomaterial, due to their characteristics of strength, inertness, as well as biocompatibility, which was characterized along with other "high performance" engineering polymers, such as polysulfones and polybutylene terephthalate in the $1990 \mathrm{~s}^{2}$ PAEKs have stability at high temperatures (exceeding $300^{\circ} \mathrm{C}$ ), resistance to chemical and radiation damage, compatibility with reinforcing agents, and greater strength per mass than many metals.

In addition to their appealing characteristics, PAEKs can be modified to suit various applications. The modulus of PAEKs can be tailored to match a variety of materials such as cortical bone or titanium (Ti) alloy by supplementing the bulk material with carbon fiber to create carbon fiber-reinforced (CFR) composites. ${ }^{3}$ The method to produce PAEK polymers by linking aromatic ketones by an ether bond, which involves a nucleophilic displacement reaction, allowed the development of additional polymer variants by use of different bisphenols to produce PAEK polymers with various properties. Eventually, the family of PAEK polymers grew to include polyether ketone, polyether ether ketone (PEEK), polyether ketone ketone, and polyether ketone ether ketone, among others, that displayed a range of glass transition temperatures $\left(143^{\circ} \mathrm{C}-160^{\circ} \mathrm{C}\right)$ and high crystalline melt temperatures $\left(335^{\circ} \mathrm{C}-441^{\circ} \mathrm{C}\right)$.

PEEK biomaterials, a variation of PAEKs, have been used in a variety of clinical applications. Much of the early work with PEEK biomaterials investigated their use in spinal implants. CFR-PEEK has also been extensively explored for bearing material applications. PEEK is now used in contemporary settings for spinal implants, femoral stems, bearing materials for hip and knee replacement, and hip resurfacing.

The popularity of PEEK increased in the late 1990s as it was considered a leading high-performance thermoplastic candidate for replacement of metal implant components. This was particularly true in orthopedics and trauma. ${ }^{1}$ A primary appeal was its resistance to in vivo degradation, including damage caused by lipid exposure. PEEK was eventually offered as a biomaterial for implants in April 1998, and as a next step, to facilitate improved implant fixation, PEEK was subsequently investigated for its compatibility with bioactive materials such as hydroxyapatite (HA) (as a composite filler or surface coating). Due to continued research efforts, PEEK and related composites can be engineered with a wide range of physical, mechanical, and surface properties for customization according to each application.

Significant research has focused on the suitability of PEEK for orthopedic applications. The biocompatibility of PEEK and PEEK composites as a family of biomaterials in bulk form have been extensively shown. ${ }^{4}$ PEEK-OPTIMA ${ }^{\circledR}$ and CFR PEEK-OPTIMA ${ }^{\circledR}$ compounds and composites have undergone biocompatibility testing to meet criteria for US Food and Drug Administration approval. However, some concern has been raised regarding the inertness of PEEK as well as its limited fixation with bone. As a result, research efforts have emphasized improving the bone-implant interface in order to increase fixation. This has been performed by producing composites with HA, by coating PEEK implants with Ti and HA, and by creating porous PEEK networks for bone ingrowth. Various toxicity studies have also demonstrated excellent biocompatibility of PEEK in animal models and in vitro cell culture models. ${ }^{4-6}$

Another study demonstrated the biocompatibility of CFR-PEEK by showing that, when samples were implanted 
in rabbit muscle, the tissue response surrounding the implants was comparable to ultrahigh-molecular-weight polyethylene (UHMWPE). ${ }^{7}$ Generally, PEEK has been demonstrated over 2 decades to be inert in its bulk state. As PEEK materials are considered to be relatively inert, there has been greater interest in modifying the polymer to stimulate enhanced bone apposition for load bearing orthopedic applications..$^{8-11}$ Therefore, bioactive PEEK composites were created by compounding PEEK with calcium phosphate $(\mathrm{CaP})$ biomaterials, such as $\beta$-tricalcium phosphate $(\beta$-TCP) and HA. In vitro studies have also shown good results regarding PEEK/HA composites and their bioactivity. However, mechanical characterization of these composites has produced mixed results. For example, loading PEEK with HA particles resulted in a significant increase in elastic modulus. ${ }^{8,10,12}$ However, in contrast with carbon and glass fiber additives, HA and $\beta$-TCP ${ }^{10}$ do not integrate well with the PEEK matrix. Researchers further showed that pure PEEK was nontoxic, but that cell proliferation was somewhat progressively inhibited with the addition of $\beta$-TCP. These results suggest that PEEK possesses good biological interaction on its own without the addition of traditionally bioactive components. PEEK-HA composites thus show promise as bioactive implants but involve a tradeoff in load carrying capacity. Further research will be required to improve the adhesion of HA particles to the PEEK matrix, or to determine which concentrations of HA particles are most suitable for specific orthopedic applications.

Recent studies have focused on PEEK composites and other novel uses for improved orthopedic applications. One in vitro study employed a self-initiated surface graft polymerization technique to create a hydrophilic and smooth $100 \mathrm{~nm}$ thick poly(2-methacryloyloxyethyl phosphorylcholine) layer on the surface of CFR-PEEK..$^{13}$ This grafted layer suppressed direct contact between CFR-PEEK and the counter-bearing surface, reducing frictional force and potentially leading to increased bearing durability. Another study tested the biomechanical and wear properties of various CFR-PEEK implants, including a tibial nail, dynamic compression plate, proximal humeral plate, and distal radius volar plate. ${ }^{14}$ All mechanical tests showed CFR-PEEK implants to have similar or improved behavior as commercially used devices as well as generating a lower volume of wear particles. CFR-PEEK was also tested in an ovine model for use as a material in cemented and cementless hip prostheses. ${ }^{15}$ The results suggested that both cementless and cemented CFR-PEEK stems with rough-textured surfaces and HA coatings may function well for fixation, but may be relatively more challenging when used as cups. A multicenter study of 182 patients with implanted CFR-PEEK proximal humeral fracture plates showed that CFR-PEEK plates were as reliable as metallic plates. ${ }^{16}$ These CFR-PEEK plates also have advantages of better visualization of fracture reduction during intraoperative fluoroscopic assessment and easier hardware removal.

\section{Polycarbonate urethanes}

Polyurethane (PU) biomaterials have been explored for 2 decades for their potential as compliant orthopedic-bearing materials. They have lower modulus values than UHMWPE and have been hypothesized to operate under a microelastohydrodynamic lubrication regime, which leads to reduced wear. ${ }^{17}$ Third generation PU biomaterials, called segmented polycarbonate urethanes (PCUs), have improved oxidative stability relative to poly(ether urethanes). PCUs have been investigated as bearing materials for total acetabular replacement due to high toughness, ductility, oxidation resistance, and biostability. ${ }^{18-20}$

PCUs are being considered as alternative materials for hard-on-soft bearings. The goal of these efforts is to reconstruct damaged or eroded cartilage in the acetabulum with softer materials that better mimic the mechanical properties and lubrication of cartilage. ${ }^{21}$ Laboratory testing of Bionate ${ }^{\circledR}$ 80A (DSM, Exton, PA, USA) (shore hardness) PCU cups showed at least 24\% lower material loss when compared with cross-linked UHMWPE. ${ }^{22}$ Even when tested at 20 million cycles, PCU liners have shown low and steady volumetric wear rates of $5.8-7.7 \mathrm{~mm}^{3} /$ million cycles. ${ }^{23}$

Biocompatibility is also of interest for PCUs due to their candidacy as a bearing material. Studies have shown that PCU particles cause less of an inflammatory response by macrophages than particles of UHMWPE. ${ }^{24}$ Because of the success of hip simulator and biocompatibility tests, work progressed to clinical studies to further characterize the viability of PCU as a compliant surface device. ${ }^{25,26}$ To date, PCU hip implants have been limited clinically to a 2006 European study related to the TriboFit ${ }^{\circledR}$ Hip System (Active Implants, Memphis, TN, USA), which is a $3 \mathrm{~mm}$ thick PCU device that can either be snap-fit directly into the acetabulum or inserted into a metal shell. Results from the first 50 cases over the course of 2-4 years of follow-up suggested that the TriboFit ${ }^{\circledR}$ Hip System was found to be as safe and effective for total hip arthroplasty use in femoral neck fracture patients as traditional hemiarthroplasty systems, as well as in osteoarthritis patients undergoing total hip arthroplasty utilizing a system made of traditional bearing materials.

Thus, as shown from results of laboratory tests, animal studies, and early clinical trials, PCU devices may be 
a promising new option for hip replacement implants. However, longer term results and research efforts are needed to determine if PCU can provide wear benefits and withstand functional use in humans.

\section{Silicon}

Silicones, which are synthetic polymers comprised of silicon (Si), oxygen, and frequently carbon and/or hydrogen, are widely used in health care and are also of interest in orthopedic applications. Silicones are traditionally known for their properties of biocompatibility and biodurability. ${ }^{27}$ The most common orthopedic applications of silicone are hand and foot joint implants, such as the silicone finger joint implants developed by Swanson. ${ }^{28}$ Similar implants were developed for the foot and hand. Even now, silicone remains the most prevalent type of small joint implant. Silicone metacarpophalangeal joint arthroplasty studies in recent years have continued to show good long-term outcomes, with high survivability and positive patient response. ${ }^{29-31}$

Silicon nitride $\left(\mathrm{Si}_{3} \mathrm{~N}_{4}\right)$ is a recent entry into the ceramic biomaterials arena for hard-on-hard hip bearings. ${ }^{32-35} \mathrm{~A}$ range of Si-based, nonoxide ceramics can be produced with varying properties that differ from those of the conventionally used $\mathrm{Al}_{2} \mathrm{O}_{3}$ by altering the composition of additives during production. ${ }^{36} \mathrm{Si}_{3} \mathrm{~N}_{4}$ has an elastic modulus of $300 \mathrm{GPa}$ and fracture toughness of $10 \mathrm{MPa} \cdot \mathrm{m}^{1 / 2}$, giving it higher strength characteristics than alumina and making Si ceramics generally suitable for total joint replacement applications. However, some concerns also exist. For example, a concern with $\mathrm{Si}_{3} \mathrm{~N}_{4}$ is superficial oxidation, which results in a $\mathrm{Si}$ oxide $\left(\mathrm{SiO}_{2}\right)$-rich layer that is several nanometers thick ${ }^{37}$ and that has been found on $\mathrm{Si}_{3} \mathrm{~N}_{4}$ and $\mathrm{SiC}$ surfaces; the thin layer has the potential to chip off over time, ${ }^{38}$ potentially resulting in significantly increased third-body wear. Biocompatibility of $\mathrm{Si}_{3} \mathrm{~N}_{4}$ may also be ceramic-formulation dependent. ${ }^{34,35}$ Despite these concerns, Si-based ceramics have continued to push forward in orthopedics. For example, a $\mathrm{Si}_{3} \mathrm{~N}_{4}$ ceramic formulation was commercialized by Amedica (Salt Lake City, UT, USA) for ceramic-on-UHMWPE, ceramic-on-ceramic, and ceramic-on-metal hip bearing applications. Wear testing of ceramic-on-metal and ceramic-on-ceramic bearings in a hip simulator demonstrated ultralow wear rates that were comparable to or lower than alumina-alumina. ${ }^{32,33}$

\section{Bioabsorbables}

The applications of bioabsorbable implants in orthopedics are largely derived from the need to eliminate implant removal operations. ${ }^{39}$ As a newer technology in orthopedic surgery, bioabsorbables are still frequently changing and evolving. Effort in bioabsorbable research has focused on developing new materials with fewer adverse effects. The first study of implantable bioabsorbable materials was performed by Kulkarni et al, ${ }^{40}$ who studied the biocompatibility of poly-L-lactic acid (PLLA) in animals (guinea pigs and rats) and found that PLLA was nontoxic and gradually degradable. Since then, multiple formulations have been developed, and the types of bioabsorbable implants now available are quite varied. For example, polyglycolic acid (PGA) has been used in pins and screws, and polylactic acid (PLA) has been implemented in a variety of implants including pins, rods, tacks, screws, and plates. Other implants such as membranes, arthroscopic and spine surgery implants (Figure 1) are also widely in use. Though growing in appeal due to their inherent advantages, some concerns of material properties do exist. A recent in vitro characterization study compared bioresorbable posterior cervical rods to commonly used Ti alloy rods. ${ }^{41}$ The bioresorbable implants were shown to have adequate shear resistance but less load resistance and stiffness compared to the Ti rods. However, the stiffness of the bioresorbable rods (16.6-21.4 $\mathrm{N} / \mathrm{mm}$ ) was similar to bone, which resulted in better gradual dynamic loading.

\section{Copolymers}

PLA and PGA have been widely used among orthopedic surgeons, and most commercially available implants are made from these two materials and their copolymers. However, recently, other bioabsorbable materials such as poly(ortho

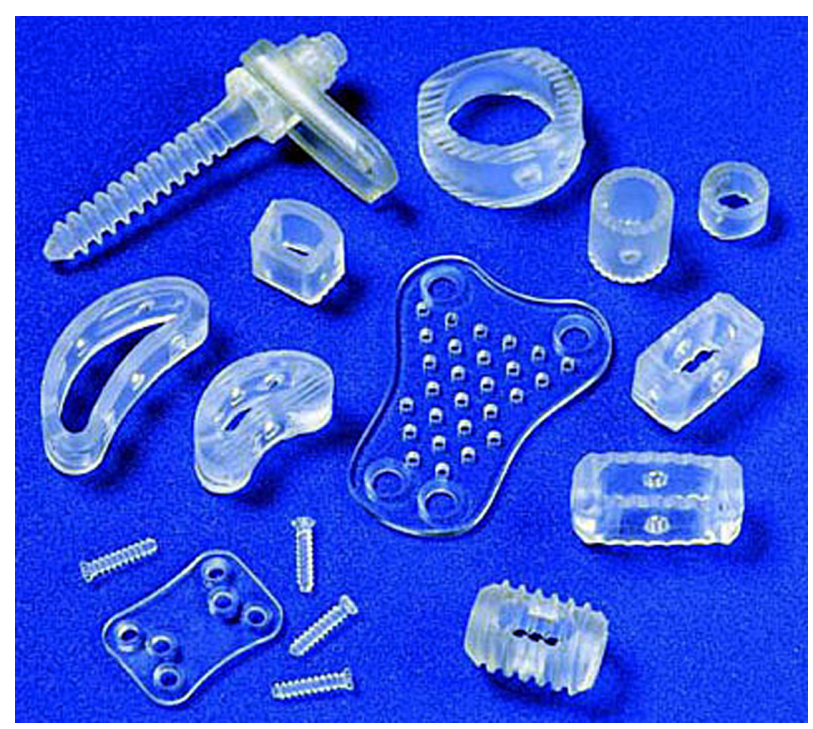

Figure I A variety of bioabsorbable implants for use in spine applications. Notes: Copyright (c) 2004 American Association of Neurological Surgeons. Reprinted with permission from the JNS Publishing Group. Reprinted from: Robbins MM, Vaccaro AR, Madigan L. The use of variables affecting convection implants in spine surgery. Neurosurg Focus. 2004; I6(3):EI. http://thejns.org/. ${ }^{205}$ 
esters), poly(glycolide-co-trimethylene carbonate), poly (p-dioxanone), poly( $\varepsilon$-caprolactone) (PCL), poly(bhydroxybutyrate) (PHB), and PHB hydroxyvaleric acid have come into use. One of the most popular copolymers currently in use, particularly in oral and maxillofacial surgery, is poly-L/D-lactide 70/30 both in simple ${ }^{42,43}$ and self-reinforced forms. ${ }^{44,45}$ However, some concerns exist with these copolymers as materials for bioabsorbable implants. One case study of nine patients who underwent posterior lumbar instrumented fusion cage implants was performed, showing osteolysis around the implant in four patients, suggesting a high osteolytic nature for poly(L-lactide-co-D,L-lactide) cages and the potentially unsuitable nature of the material for a fusion cage. ${ }^{46}$ Another concern of bioabsorbable implants is the unclear definition of their resorption properties. A study of bioabsorbable poly(lactic-co-glycolic acid) (PLGA) screws used in anterior cruciate ligament surgery was performed examining 67 patients (134 screws) and showed that 3 years after surgery the majority of cases had remains of screws still present. ${ }^{47}$

\section{Degradation, tissue reaction}

Some concerns with PLA and PGA and their copolymers are degradation and subsequent tissue reaction. The enantiomeric isomers of PLA, the L-isomer and the D-isomer, have different properties. The L-isomer (PLLA) has prolonged degradation time (up to several years), thereby making it similar to nondegradable materials with possible adverse reactions occurring at the final stages of polymer degradation. As the polymers are degraded, they are broken down into their final byproducts, $\mathrm{CO}_{2}$ and $\mathrm{H}_{2} \mathrm{O}$, which are then excreted or used by the body. As the polymer continues to degrade, it produces products that lower the local $\mathrm{pH}$ and cause a positive feedback that further accelerates the degradation of polymer. The crystallinity of a polymer, which specifies its hydrophobicity, also affects the speed of degradation, as amorphous and hydrophilic materials allow greater contact between water molecules and the material, thus increasing the hydrolysis speed.

Tissue reactions are a main clinical issue for bioabsorbable materials as a whole. Some studies of patients with pins, rods, bolts, and screws made of PLA or PGA have shown inflammatory foreign body reactions with polymer debris surrounded by mononuclear phagocytes and multinucleated giant cells. ${ }^{48}$ Adverse tissue reactions include a range of symptoms and signs from mild fluid accumulation to reactions that require active and/or immediate treatment. Böstman and Pihlajamäki ${ }^{48}$ presented serious reactions in patients with PGA implants (pins, rods, bolts, screws), with an acute onset with a painful erythematous fluctuating papule over the implant track. In the same study, radiographic examination of the patients with adverse reactions revealed osteolysis around the implant in $57.4 \%$ of the cases. Tissue reaction to absorbable materials can also present with synovitis. Material scientists have thus focused on the degradation behavior of implants and the development of new materials to optimize their properties to avoid such adverse reactions.

The use of PGA is now limited, since materials and copolymers with better degradation properties have become available. PLLA has a low degradation rate, and adverse reactions tend to appear up to 4-5 years postoperatively. A review of the first clinical trials where PLLA implants were used ${ }^{48}$ presents a wide variety of reaction rates, from no adverse reactions to swelling in $47 \%$ of the patients. Advances such as self-reinforcement technique and elimination of factors that were considered responsible for reaction (eg, dyes and older sterilization techniques) have changed PLLA implant behavior. Enantiomeric isomers of PLA were mixed to develop a material less crystalline and more hydrophilic than PLLA in order to accelerate the degradation process and avoid late tissue reactions. Self-reinforced technique was introduced $^{49}$ later and resulted in better mechanical properties of implants.

Recent studies have shown that infection remains somewhat of a concern for bioabsorbable implants, but with improving results. One multicenter retrospective study of bioabsorbable pins used for periarticular fractures (80 fractures in 78 patients) showed an infection rate of $6 \% .{ }^{50}$ Another study of 59 hips undergoing less invasive innominate osteotomy for persistent or delayed diagnosis developmental dysplasia of the hip explored the complication rates of bioabsorbable pins used for surgery. ${ }^{51}$ The study showed no incidence of postoperative wound infection or other complication requiring medical or surgical intervention. Another study of an experimental bioabsorbable cage consisting of magnesium and polymer (PCL) was performed in an ovine animal model. ${ }^{52}$ In this study of 24 sheep, no wound healing or infectious problems were observed for the bioabsorbable cages up to 24 weeks after surgery.

\section{Composites}

Composites formed from a combination of PLA copolymers and bioactive ceramics with higher modulus values have been explored in recent studies. By controlling the filler content in the composite, manufacturers are able to customize the material properties of the bioabsorbable products. A common example of a bioactive ceramic filler is TCP, and research has focused on $\beta$-TCP and its effects on overall composite material properties. The use of $\beta$-TCP, which has 
a higher modulus than PLA, in varying fractions allows for the customization of the final composite material modulus. An in vitro study by Kobayashi and Yamaji ${ }^{53}$ demonstrated that interfacial strength of the composite material was independent from $\beta$-TCP fraction. In a recent in situ study, use of PLA/ $\beta$-TCP composites for spinal fusion cages was explored. ${ }^{54}$ The use of PLA- $\beta$-TCP for a bioabsorbable cervical fusion cage resulted in improved stability compared to autologous tricortical iliac crest bone grafts and PEEK cages in single-level anterior cervical discectomy and fusion models in sheep. This demonstrated a potential alternative to the current PEEK spinal cages.

The degradation properties of a PLLA- $\beta$-TCP composite were explored by Adamus et al. ${ }^{55}$ The compression molded samples were subjected to in vitro degradation for 1 year. Some immediate decay in flexural strength and an increase in stiffness were observed after addition of $\beta$-TCP. However, these parameters remained stable thereafter for the 1-year period of study. Another recent study ${ }^{56}$ demonstrated that using bioactive ceramic fillers for PLLA/ $\beta$-TCP $(30 \%$ or $60 \%$ $\beta$-TCP) screws for anterior cruciate ligament reconstruction procedures had no effect on clinical outcome. The addition of $\beta$-TCP, however, minimized inflammatory response, and the study showed that $\beta$-TCP increased the resorption rate of the orthopedic implant.

Bioabsorbables represent a promising new field in orthopedic surgery, due to their inherent appeal in eliminating the need for revision or removal surgery. As a newer field, primary complications of adverse tissue reactions and degradation must be improved upon before widespread use in a variety of orthopedic applications. However, recent studies in eliminating these complications, while using composite fillers to modify material properties as desired, continue to make bioabsorbables a highly interesting topic in orthopedic research.

\section{Tissue engineering}

Tissue engineering and regenerative medicine seek to achieve structural and functional tissue repair and/or regeneration using natural signaling pathways and components such as stem cells, growth and other signaling factors, and scaffolds. ${ }^{57-59}$ Tissue engineering may provide an alternative solution in orthopedics to traditional interventional methods, including the use of grafts, which is limited by donor site availability, rejection, disease transfer, postoperative morbidity, and harvesting costs. ${ }^{58,60}$ The major approaches to achieve effective tissue engineering include cell-based therapies, delivery of bioactive molecules, the implementation of scaffold materials, or a combination of the aforementioned factors (Figure 2). ${ }^{59,60}$ The types of materials, cells, and growth factors that are selected vary depending on the tissue/organ that is being targeted; however, there is generally a set of requirements that all scaffolds must fulfill in order to be viable for tissue engineering applications: 1) biocompatibility, 2) mechanical support, 3) porosity, and 4) bioresorbability. ${ }^{60,61}$

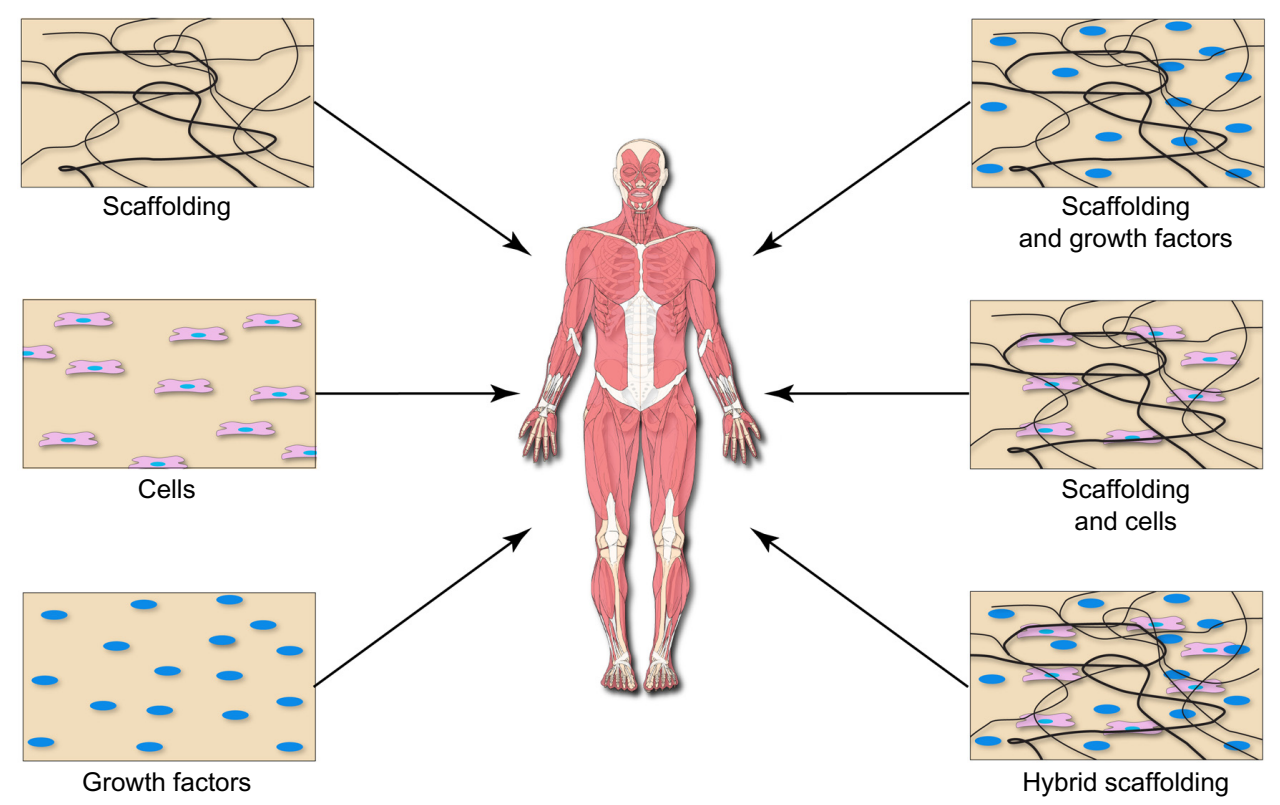

Figure 2 Tissue engineering and regenerative medicine rely on the implementation of various cell-, biomolecule-, and scaffold-based approaches to restore structure and function to developing and/or damaged tissues.

Note: Factors can be applied individually or in combination to achieve their desired effects. ${ }^{206}$ 
Natural and synthetic scaffolds have been utilized for orthopedic applications in bone, cartilage, ligament, meniscus, and intervertebral disc tissue engineering. ${ }^{58}$ Synthetic scaffolds are attractive because of the ability to tailor their biomechanical properties by altering the material composition and processing steps. However, synthetic materials are less biocompatible, and there may be concerns that their degradation byproducts may be toxic to the surrounding tissue environment. Materials such as PLA, PGA, PCL, and PHB have been studied for bone tissue engineering, while materials such as PLA have been examined for use in ligament tissue engineering. ${ }^{62}$ Naturally derived scaffolds, on the other hand, are primarily based on extracellular constituents such as collagen, fibrin, hyaluronic acid, or other biologically derived components such as alginate. These materials are inherently biocompatible and have limited toxicity; however, they have relatively weak mechanical properties, and their degradation characteristics are relatively more difficult to control compared to synthetic scaffolds. ${ }^{63}$ Hyaluronic acid, polyglactin, collagen, fibrin, alginates, chondroitin sulfate cross-linked hydrogels, and glycosaminoglycans have been studied for use in cartilage and intervertebral disc tissue engineering. ${ }^{64,65}$

More recent developments in tissue engineering have focused on basic engineering and biological fundamentals to use cells, signaling factors, and the scaffold material itself to better restore tissue and organ structure and function.

\section{Scaffolds}

\section{Bone}

The most effective biomaterials for bone regeneration are bioceramics; two of the most commonly used materials are HA and TCP. ${ }^{66}$ To improve the efficacy of HA CaP scaffolds used in bone tissue engineering, several different approaches have been studied, such as modification of scaffold chemistry, seeding of bone marrow stem cells, and incorporation of growth factors, such as transforming growth factor- $\beta$ (TGF- $\beta$ ), bone morphogenetic protein (BMP), and vascular endothelial growth factor (VEGF) into the scaffold. ${ }^{61}$

Previously, it has been shown that incorporation of silicate into HA scaffolds can enhance the scaffolds bioactivity ${ }^{67}$ and can further enhance the cell adhesion of human osteoblasts grown in culture. ${ }^{68,69}$ Other in vitro studies on the inclusion of Si in HA scaffolds have shown that osteoblast proliferation and morphology are dependent on Si content, and that there may be an optimal concentration for cells. ${ }^{70}$ Similar research efforts have shown that including Si in HA improves the biological activity of the scaffold. ${ }^{11-76}$
Researchers have shown that osteoinduction is associated not only with material composition, but also with porosity. For example, it was shown that a hybrid scaffold composed of Si-stabilized TCP/HA with $60 \%$ porosity led to greater osteoconduction than an HA scaffold with $80 \%$ porosity. ${ }^{77}$

More recently, it was shown that when mesenchymal stem cells are seeded in collagen hydrogels, the cells secreted higher levels of osteocalcin and deposited greater amounts of Ca compared to two dimensional cultures. ${ }^{78}$ When the cells were further stimulated with osteoinductive supplements, the construct cultures developed improving biomechanical properties, including high stiffness and burst strength, as well as morphological characteristics typically found in bone. Furthermore, these constructs had increases in stiffness and ultimate burst strength in a time-dependent fashion, suggesting that mesenchymal stem cells were undergoing osteoblast differentiation. In a similar study, $\mathrm{CaP}$ cement scaffolds coated with collagen were seeded with human umbilical cord mesenchymal stem cells, and it was shown that the mesenchymal stem cells exhibited excellent proliferation, differentiation, and synthesis of bone minerals. ${ }^{79}$ Importantly, combination cell and scaffold implants may also translate to in vivo applications. In a severe combined immunodeficiency mouse model, human umbilical vein endothelial cells and mesenchymal stem cells were seeded either alone or in a decalcified, processed bovine cancellous bone and implanted into calvarial critical-sized defects. ${ }^{80}$ In the coimplantation group, neovessel formation was considerably higher, and mesenchymal stem cells supported bone formation.

In addition to cell-enriched scaffold therapies, growth factors have also been shown to play critical roles in tissue engineering. In a $5 \mathrm{~mm}$ diameter cranial bone defect in rats, when a PLLA-based scaffold is enriched with BMP-2 or a synthetic BMP-2-related protein, bone is deposited more rapidly than in pure scaffolds. ${ }^{81}$ In a critical size cranial defect model in Balb/c mice, $\mathrm{CaP}$ scaffolds enriched with $5 \mu \mathrm{g} / \mathrm{mL}$ VEGF demonstrated increased blood vessel density and higher bone deposition in the macropores of the scaffold compared to the scaffold-only group..$^{82}$ It was further shown that the VEGF release kinetics were vital to these processes as short-term release of VEGF resulted in temporary restricted angiogenesis and did not enhance bone formation. Other studies have further corroborated these findings, in which scaffolds loaded with both BMP-2 and VEGF demonstrated enhanced vascularization and new bone formation. ${ }^{83-85}$

In vitro and in vivo studies have shown promise for hybrid bone scaffolds in terms of restoring both structure and function to the bone. However, challenges still remain in 
optimizing the scaffold characteristics to fully restore bone functionality. The scaffold must be initially strong enough to withstand the mechanical forces of the microenvironment; however, it should also degrade and allow natural bone formation to take place to restore the natural structure and function of the bone. This balance is made more difficult by the heterogeneous nature of bone, which is composed of cortical bone and cancellous bone, each of which has distinctly different mechanical properties, compositions, and porosities. Therefore, the ideal bone scaffold should also have microdomains that reflect these differences in material characteristics.

\section{Cartilage}

Complete repair of cartilage is extremely difficult to achieve because it has a minimal vascular network and has little metabolic activity. There are inherent difficulties associated with current treatments such as viscosupplementation, chondrocyte transplantation, and the use of autografts or allografts, therefore, the use of scaffolds for cartilage tissue engineering has gained traction. Many of these scaffolds rely on surface modification techniques to promote functionality. For example, various surface peptides have been cross-linked to PCL or polyethylene oxide/chitosan-based scaffolds to enhance mesenchymal stem cell recruitment, improve adhesion and proliferation of chondrocytes, and stimulate chondrogenesis with enhanced quantities of glycosaminoglycans and collagen both in vitro and in vivo. ${ }^{86-88}$ By adding bioglass to agarose scaffolds, the biochemical and mechanical properties of the tissue-engineered cartilage layer were improved; with another approach, coating PHB-valerate with bioglass resulted in improved hydrophilicity and promoted cell migration into the inner part of the constructs, and, when implanted into rabbits, resulted in thicker cartilage-like tissue with improved biomechanical properties with more cartilage matrix content than constructs without bioglass. ${ }^{89,90}$ Other scaffolds composed of silk, gelatin-methacrylamide, PLGA, or collagen have been coated with hyaluronic acid. These studies showed that the scaffolds had improved structural and physical properties as well as improved cellular infiltration and early-stage chondrogenesis in vitro. ${ }^{91-94}$ Finally, chitosan has also been used to coat poly-L-lactic-co-E-caprolactone, silk fibroin, and gelatin scaffolds, which resulted in improved cell functionality in culture and cartilage regeneration in rabbits..$^{95-97}$

Other scaffold approaches have incorporated small signaling molecules to promote functionality. For example, incorporating parathyroid hormone-related protein with a collagen-silk scaffold inhibited differentiation of chondrocytes and resulted in enhanced chondrogenesis, cartilage repair, and regeneration in rabbits. ${ }^{98}$ Cell culture studies have also incorporated TGF- $\beta$ into scaffolds, which resulted in greater production of glycosaminoglycans and total collagen by annulus fibrosus cells. ${ }^{99}$ Cadherin-II, on the other hand, was shown to promote adhesion of chondrocytes and stimulate differentiation. ${ }^{100}$

\section{Spinal cord}

Spinal cord injury severity depends on the type and intensity of the injury. The primary mechanical injury leads to damage of nerve fiber pathways in the white matter, while secondary degeneration includes apoptosis, bleeding, excitotoxicity, free radical production, inflammation, ischemia, edema, scarring, and cystic cavitation, which all also contribute to tissue loss. ${ }^{11,102}$ Other natural processes such as intervertebral disc degeneration can also lead to back pain. Usual approaches to treating such degeneration include disc excision and vertebral body fusion or artificial total disc replacement; however, these approaches are traumatic, and may cause adjacent disc degeneration and may degrade over time. Because of the complexity of the pathophysiology associated with spinal cord injury and/or degeneration, other approaches to treating restoring functionality have been attempted including celland gene-based therapies; drug, antibody, or growth factor delivery; and the incorporation of biomaterial scaffolds. ${ }^{103}$

Various naturally derived extracellular matrix (ECM) scaffolds have recently been used in attempts to restore functionality in spinal cord injury. These scaffolds have utilized collagen, fibrin, fibronectin, agarose, hyaluronic acid, and chitosan. ${ }^{104}$ In one study, combinatorial agarose scaffolds were implanted into the spinal cord dorsal columns of rats that had been transected at the $\mathrm{C} 4$ level. ${ }^{105}$ The combinatorial scaffolds were patterned and seeded with autologous bone marrow stromal cells expressing neurotrophin-3 and were combined with lentiviral vectors expressing neurotrophin-3 as well as lesions of sensory neuronal cell bodies. These scaffolds resulted in organized and linear axonal regeneration. In another study, agarose scaffolds seeded with marrow stromal cells that secreted brain-derived neurotrophic factor were implanted into rat spinal cords that had been completely transected. ${ }^{106}$ Although the scaffolds were shown to support linear motor axon regeneration into the injury site, it was shown that the growth factor further enhanced the axonal growth. Chitosan tubes containing type I collagen have also been shown to promote successful restoration of functionality in spinal cord injury in rats. ${ }^{107}$ At 1 year after implanting the scaffolds, researchers found that axons from the proximal side of the spinal cord injury regenerated and traversed the 
transected section of the spinal cord (4 $\mathrm{mm}$ in length and $2 / 3$ of the cord width), which led to functional restoration of the previously paralyzed hind limbs. Interestingly, the control groups, in which one of the components of the combinatorial scaffold was omitted, were much less efficacious in restoring functionality to the injured site in these studies, suggesting that there is a complex interplay between cells, the extracelluar matrix, and the surrounding extracelluar milieu in enhancing tissue regeneration.

Similarly, hybrid scaffolds utilizing synthetic polymers have also been successful in enhancing repair of spinal cord injury. Three-dimensional (3D) gelatin sponge scaffolds seeded with or without bone marrow-derived mesenchymal stem cells were implanted into transected rat spinal cords. ${ }^{108}$ Scaffolds were biocompatible and enabled the stem cells to adhere, proliferate, and deposit fibronectin. The cell-seeded scaffolds were further shown to reduce inflammation, promote angiogenesis, and reduce cavity formation. In another study, scaffolds fabricated from poly(D,L-lactide-co-glycolide)/ small intestinal submucosa and seeded with or without bone marrow stem cells were implanted into completely transected rat spinal cords. ${ }^{109}$ The scaffolds with cells were shown to promote axonal regeneration, enable survival of the stem cells, and promote functional recovery in the hind limbs. Other combinatorial therapy of a PCL scaffold enriched with neural stem cells, neurotrophin-3, and chondroitinase resulted in improved cell viability and locomotor recovery following spinal cord injury in a rat hemisection model. ${ }^{110}$

\section{Skeletal muscle}

Skeletal muscle generally has the ability to regenerate following injury. However, in some disease states, such as Duchenne muscular dystrophy, or huge loss of tissue due to trauma or tumor ablation, intrinsic repair mechanisms are insufficient to repair the natural state of the muscle, and other treatment approaches are needed to restore structure and/or function. ${ }^{111}$

Cell-based therapies are one treatment used to increase the local concentration of cells with myogenic potential, and to that end, various stem/progenitor cells have been investigated. ${ }^{111}$ Cell types that have been investigated include myoblasts, CD133+ progenitor cells, muscle-derived stem cells, multipotent perivascular progenitor cells, muscle side population cells, bone marrow-derived mesenchymal stem cells, adipose-derived mesenchymal stem cells, and umbilical cord blood-derived mesenchymal stem cells. These cells can be administered systemically or injected locally into the site of injury. However, when injected systemically, the cells may attach to other sites like the liver or spleen, ${ }^{112}$ and when injected locally, the cells may not effectively redistribute to promote sufficient healing of the injured site. ${ }^{113}$

Because of the limitations associated with cell-based therapies, both synthetic and naturally occurring scaffolds have been implemented in tissue engineering applications for skeletal muscle repair. For example, a collagen-coated porous scaffold made of poly-lactide-co-glycolide (PLG) has been investigated. The scaffold promoted myogenic differentiation in vitro, but when implanted in a mouse model, the PLG scaffolds only resulted in $22 \%$ donor cell viability ${ }^{114}$ due to the presence of host-derived natural killer cells. Other PCL-based scaffolds with unidirectionally oriented nanofibers have also been shown to promote muscle cell alignment and myotube formation in vitro. ${ }^{115}$

Multiple naturally derived scaffold approaches have been developed for use in skeletal muscle tissue engineering. Collagen composite scaffolds have been seeded with murine myoblasts and implanted into skeletal muscle defects created in mice. ${ }^{116}$ It was shown that the grafts slowly degraded over time, and that muscle healing was improved as demonstrated by an increased number of innervated and vascularized regenerated muscle fibers. In a mouse model of Duchenne muscular dystrophy, a collagen I-based tissue engineered construct seeded with myogenic precursor cells resulted in lower apoptosis and higher proliferation of injected cells, as well as greater restoration of dystrophin than cell-only injections. ${ }^{117}$

Decellularized mammalian ECM has also been investigated as a scaffold because it may better promote myogenic progenitor cell differentiation from the presence of natural tissue-specific factors, such as the 3D architecture, surface ligands, and the appropriate chemical and mechanical microenvironment. ${ }^{118,119}$ For such constructs, it appears that preconditioning in vitro affects biologic properties and subsequent behavior of the scaffold. For example, in vitro mechanical loading was shown to improve cell scaffold integration and influence myogenesis prior to transplantation into mice. ${ }^{120,121}$ Machingal et al ${ }^{121}$ further showed that mechanical preconditioning of primary human muscle precursor cells seeded onto an acellular bladder produced 75 -fold greater contractility compared to previous reports.

\section{Injectables Cartilage}

Healthy adult knees contain approximately $2 \mathrm{~mL}$ of normal synovial fluid that acts to transport nutrients to chondrocytes and also lubricate articular cartilage. ${ }^{122}$ The synovial fluid in osteoarthritic knees contains elevated levels of free radicals, 
inflammatory cytokines, and cleavage enzymes, which contribute to reduced hyaluronic acid concentration as well as subsequent articular cartilage damage and the progression of osteoarthritis. ${ }^{123-126}$ Although total knee arthroplasty provides excellent long-term results for older patients with severe osteoarthritis, the risks of revision surgery or complications may be elevated for younger patients. One alternative treatment option for such patients may be viscosupplementation or the injection of hyaluronic acid. ${ }^{127}$

Hyaluronic acid was approved for use as a biological product in the United States in 1997, ${ }^{128,129}$ and several formulations are currently available: Hyalgan, Synvisc, Supartz, Orthovisc, and Euflexxa. ${ }^{127}$ There have been several recent meta-analyses analyzing the efficacy of viscosupplementation in the treatment of osteoarthritis. ${ }^{130-132}$ However, the results of the studies were inconsistent regarding the benefits of the treatment with respect to differential efficacy effects for different products, due likely to the formulations/molecular weight. Campbell et al ${ }^{131}$ found a probable therapeutic benefit for pain reduction and physical function improvement, while Bellamy et al ${ }^{130}$ found statistically significant benefits compared to placebo for pain, function, and patient global assessment scores. However, Rutjes et al ${ }^{132}$ determined that viscosupplementation only provides a clinically irrelevant and small benefit.

Several societies have also reviewed the efficacy of viscosupplementation and have issued guidelines regarding its use. The Osteoarthritis Research Society International (OARSI) has issued several recommendations for the management of hip and knee osteoarthritis, including nonsurgical approaches such as viscosupplementation. ${ }^{133-135}$ Following two versions in 2008 and 2010, OARSI published their latest recommendations in 2014 for nonsurgical management of knee osteoarthritis and recommended that intra-articular injection of hyaluronic acid is "not appropriate" for multiple joint osteoarthritis, and the efficacy is "uncertain" for knee only osteoarthritis due to inconsistent conclusions among the meta-analyses and conflicting results, but they also noted that a number of studies revealed positive effect sizes for pain. ${ }^{133}$ Similarly, the American Academy of Orthopaedic Surgeons (AAOS) also issued clinical practice guidelines for the treatment of knee osteoarthritis. ${ }^{136}$ AAOS also revised their recommendations of the use of hyaluronic acid for treatment of knee osteoarthritis in 2013, in which the AAOS could not recommend hyaluronic acid for patients with symptomatic osteoarthritis of the knee. ${ }^{137}$ Although their meta-analysis showed statistically significant treatment effects based on Western Ontario and McMaster Universities Osteoarthritis
Index pain, function, and stiffness, they stated that none met the minimum clinically important improvement thresholds. It was further noted that high molecular weight hyaluronic acid was associated with most of the statistically significant outcomes. Although viscosupplementation with hyaluronic acid may be a viable treatment option, recent guidelines have cautioned against its use due to study heterogeneity, outcome reporting, and publication bias. Continued differentiation of hyaluronic acid formulations is warranted to determine their respective efficacy so as to better discern potential benefits for specific hyaluronic acid formulations.

Although there has not been consensus regarding the efficacy of viscosupplementation in the treatment of osteoarthritis, research efforts continue to investigate hyaluronic acid-based hydrogels. Owing to its structure, hyaluronic acid can be modified with a variety of side chains to impart various properties to the hydrogel. Chemical modifications with thiols, haloacetate, dihydrazides, aldehydes, and tyramines, for example, have enabled hyaluronic acid hydrogels to be tuned such that they can undergo dynamic cross-linking - meaning they can form new bonds and therefore have altered material properties, such as permeability and stiffness, in the presence of cells, tissues, and other molecules. ${ }^{138,139}$ These hydrogels can be tuned in vitro or in situ to achieve their desired properties that offer the ability to create optimal environments for cell survival, viability, and further ECM production. For example, by incorporating hyaluronic acid into a chitosan-based hydrogel, it was shown that chondrocytes had increased proliferation and enhanced ECM deposition compared to chitosan hydrogels alone in cells grown in culture. ${ }^{140}$ By altering the cross-linking characteristics of the gel, cell viability and ECM production could also be optimized. Other studies have found similar results, demonstrating that engineering hydrogels for effective cartilage regeneration will likely require hydrogels with the appropriate stiffness and porosity, inclusion of growth factors and cell densities to achieve prolonged cell viability and ECM deposition. ${ }^{141-143}$

\section{Spinal cord}

One of the inherent challenges in designing biomaterials that can be used to heal spinal cord injury is to match their mechanical properties to those of the spinal cord. The elastic modulus of the spinal cord is approximately $230 \mathrm{kPa},{ }^{144}$ while that of gray/white matter is $2-5 \mathrm{kPa},{ }^{145}$ thus it can be extremely difficult to design stable biomaterials with not only stiffness as low as a few kPA, but also with multiple stiffness that differ by a factor of 100 . Such a challenge was highlighted by hydrogel "guidance channels" that had similar mechanical 
characteristics to the spinal cord. ${ }^{144,146}$ The hydrogels that hold the proximal and distal ends of transected spinal cords are filled with gel-like matrix or glial cells and as a result promote axonal ingrowth on the inner surface of the hydrogel tubes. During implantation, however, the gels collapsed and efforts were made to increase the gel's stiffness. Although the channels became more resistant to deformation, the additional stiffness led to syringomyelia of the spinal cord. ${ }^{147}$

Other naturally derived and synthetic polymer-based hydrogel systems have more recently been investigated for their ability to enhance recovery after spinal cord injury. For example, hydrogels consisting of collagen, fibronectin, fibrin, and fibrin/fibronectin were injected into cavities in rat spinal cords. ${ }^{148}$ Each of the four ECM scaffold materials was able to integrate with the host spinal cord and promote some axonal ingrowth. However, collagen scaffolds had uneven axonal ingrowth, and fibronectin scaffolds had large cavities between the scaffold and host spinal cord. Furthermore, fibronectin scaffolds in the intact spinal cord surrounding the implant site had fewer surviving neurons. It was therefore determined that the fibrin/fibronectin scaffold was superior to others because it promoted the greatest axon growth and integrated the best with the host spinal cord. Another naturally derived polymer that has gained traction is hyaluron/hyaluronic acid. One study investigated hyaluronic acid hydrogels modified with polyL-lysine and nogo-66 receptor antibody in a model of lateral hemisection of a rat spinal cord, and it was shown that the hybrid scaffolds facilitated greater cell viability and a greater amount of axon myelination compared to scaffolds alone. ${ }^{149}$ Another study investigating a hyaluronic acid-based hydrogel functionalized with a metalloproteinase peptide cross-linker, a peptide derived from laminin, and brain-derived neurotrophic factor showed that these factors play roles in mesenchymal stem cell differentiation in vitro. ${ }^{150}$ When hydrogels were further injected into the intrathecal space of rats subjected to spinal cord injury, the hybrid scaffold with brain-derived neurotrophic factor produced the greatest improvement in locomotive function over the course of 6 weeks. Yet another study used a hydrogel of hyaluronan and methyl cellulose, which was further modified by covalent bonding recombinant rat platelet-derived growth factor. ${ }^{151}$ When the hydrogels were seeded with adult brain-derived neural stem/progenitor cells and injected into a subacute, clinically relevant model of rat spinal cord injury, the hydrogels significantly reduced cavitation and improved cell viability and graft survival. Synthetically derived hydrogels have also been successfully used to treat spinal cord injury. A hydroxypropyl methacrylamide hydrogel with attached Arg-Gly-Asp (RGD) sequences and seeded with mesenchymal stem cells was used to treat acute spinal cord injury in rats. The hydrogel promoted improved motor/sensory behavior, prevented tissue atrophy, and facilitated axonal and blood vessel growth within the implant. ${ }^{152}$ Clearly there are many factors at play in achieving effective restoration of the spinal cord after injury as demonstrated by the diversity of scaffold materials as well as supplemental linker molecules, growth factors, and cell types that are incorporated into the hybrid scaffolds to promote wound healing and tissue regeneration. Furthermore, it is apparent from many of these studies that effective tissue regeneration is a multifactorial process, and that one factor alone is not sufficient to achieve functional recovery after injury.

\section{Coatings}

The industry has continuously sought to improve coatings to supplement the function of existing implants, with the goal of improving their osseointegrative qualities and incorporating antimicrobial properties. The following should be considered for these coatings: ${ }^{153}$ 1) biocompatibility, 2) osteoconductive abilities, 3) osteoinductive abilities, and 4) adequate mechanical strength of the coating-implant interface. With these criteria in mind, technological improvements in manufacturing, cell biology, and material science have led to the development of novel coatings to further improve the effectiveness of the implants. In addition, a key consideration is also the ability of the coating to be manufactured in a highly reproducible, cost effective manner. ${ }^{154}$

\section{BMP coatings}

Biological coatings with growth factors, such as TGF- $\beta 2$ and BMP-2, have been incorporated on metallic implants to help improve their osteoinductivity. ${ }^{153}$ TGF- $\beta$ helps stimulate chemotaxis and promotes the proliferation of osteoprogenitor cells and osteoblasts, while BMP-2 (which is normally secreted by osteoblasts and osteoprogenitor cells) facilitates osteoblastic differentiation of mesenchymal stem cells. Of these, BMP is the most commonly used growth factor to enhance osseointegration of metallic implants, and other advanced coatings that incorporate BMP into various biomaterials and orthopedic applications may also be able to take advantage of its osteoinductive properties.

BMP can be incorporated into metallic implants through several methods. ${ }^{155}$ One method is direct adsorption, whereby the growth factor is adsorbed to the implant surface through noncovalent interaction. However, this approach provides relatively low growth factor retention time and inconsistent release. To help delay the release of BMP to the environment, 
the use of a covering layer, such as an alginate layer, may be used. ${ }^{156}$ Another approach is to combine BMP-2 and CaP coatings to take advantage of the osteoinductivity of BMP-2 and the osteoconductivity of $\mathrm{CaP}$. The functionality of BMP coatings has further been demonstrated in animal studies with the use of Ti alloy implants coated with biodegradable, drug-loaded chitosan-tripolyphosphate nanoparticles with BMP-2. ${ }^{157}$

\section{Bisphosphonates}

Bisphosphonates are commonly used to treat osteoporosis by inhibiting osteoclastic bone resorption and promoting net bone deposition. ${ }^{153}$ The use of bisphosphonates as an implant coating has also been explored via an interposing layer of $\mathrm{CaP}$ or fibrinogen. Some researchers have suggested that the relative effectiveness of the bisphosphonate-loaded coatings is dependent on the type of bisphosphonate based on a rat study. ${ }^{158}$ The effectiveness of bisphosphonate-loaded implants may not only be limited to an osteoporotic bone environment as these types of implants have been shown to provide improved osseointegration in nonosteoporotic healthy bone in animal studies. ${ }^{159,160}$ Bisphosphonates released from surface coatings appear to be a viable method to increase periprosthetic bone density and improve overall implant stability. ${ }^{154}$ Whether these effects are temporary or can be maintained in the longer term requires further investigation, and dosing requirements must also be determined to avoid any potential adverse systemic effects.

\section{Calcium phosphate}

CaP-like HA constitutes about $50 \%-60 \%$ weight of bone and also forms an integral part of natural apatite bone minerals, ${ }^{153,154,161}$ thus providing a natural choice as a coating material. CaP-based coatings can exist in various phases depending on the concentration of soluble $\mathrm{CaP}^{153}$ Specifically, HA is relatively insoluble, while TCP and brushite are relatively more soluble. Hence, the morphology and chemical composition of the $\mathrm{CaP}$ may be modified to maximize its osteoinductive potential. Increased amounts of TCP in TCPHA combinations can also improve their osteoinductivity due, at least in part, to TCP's ability to introduce pores as it dissolves, as well as to promote bioactive apatite deposits on the coating. On the other hand, when excessive porosity is introduced, the structural integrity of the coating may be compromised. Thus these trade-offs must be considered when developing a coating.

Inorganic ions may also be incorporated into HA to better mimic the mineral component of bone. ${ }^{162}$ For example, strontium ( $\mathrm{Sr}$ ) has been considered as an additive because it is a trace element that stimulates bone cell growth and suppresses osteoporosis. Using a rabbit model, $20 \% \mathrm{Sr}-\mathrm{HA}$ coated implants induced marked improvements in the behavior of bone formation, quantity and quality of bone tissue around the implants than the control HA implant, with boneimplant contact increased by $46 \%$ and the pullout strength increased by $103 \%{ }^{163} \mathrm{Si}$ is also another possible inorganic component that can be combined with HA, because it is believed to be an essential trace element for bone regeneration. ${ }^{162}$ The potential benefits of Si incorporation were demonstrated in in vitro studies of bone marrow-derived osteoblastic cells, which showed that plasma spraying Si-HA coatings on Ti substrates provides improved biological responses in terms of cell proliferation and differentiation compared to HA coatings. ${ }^{164}$

HA coatings can be altered by doping with antibiotics to improve their antimicrobial efficacy and osseointegrative properties. Through in vitro studies, antimicrobial-loaded $\mathrm{Ca}$ HA laser deposited on Ti surfaces has shown good biocompatibility, human cell adhesion, and local antimicrobial efficacy. ${ }^{165}$ Silver-doped HA powder has also been used for plasma spray coatings on commercially pure Ti substrates with promising antimicrobial properties, while not altering its adhesion strength to the substrate. ${ }^{166}$ Further advances in the development of HA coatings have explored bioactive hybrid composite CaP-based coatings containing organic components such as collagen and BMPs, among others, to promote tissue ingrowth and vascularization. ${ }^{162}$

\section{Antimicrobial}

Efforts have been made to develop anti-infective biomaterials as a primary means to prevent medical device-associated infections. They may not only possess anti-infective bioactive properties, ie, serve as a barrier for bacterial adhesion, but may also be employed in the local delivery of antimicrobials or anti-infective medical substances. ${ }^{167}$ Antifouling coatings, such as $\mathrm{Si}_{3} \mathrm{~N}_{4}$ and silk sericin-functionalized Ti surfaces, which aim to reduce bacterial adhesion are undergoing development. While antifouling surfaces have their advantages, these coatings could possibly inhibit tissue adhesion and integration of orthopedic implant devices that rely on tissue integration. Silver, zinc, and copper, some polymeric materials, such as chitosan and its potentiated derivatives, and various bioactive glasses are also known to be intrinsically bioactive materials with antibacterial properties. At present, silver has become one of the most widely used anti-infective substances in the form of thin nanocoatings, doped solid, or 
hydrogel materials, or a component of bioactive alloys, due to its role in damaging the bacterial outer membrane, leading to cell death. ${ }^{166}$

A number of biodegradable polymers have been developed that can prevent bacterial adhesion by sloughing off the adhered bacteria. ${ }^{168}$ These resorbable polymers, including polylactides, glycolides, and lactones, are primarily designed as time-released coatings, with intentional degradation within about 10 weeks, followed by controlled drug release for another $2-3$ weeks. The degradation rate may be modulated by thermally cross-linking the polymer layer for varying periods of time.

One of the approaches to the prevention of infection is to provide an implant surface with adhesion-resistant coatings, which limits the ability of microbes to strongly adhere via chemical bonds to the implant. ${ }^{168}$ These may include polymer brushes or diamond-like carbon coatings. Polymer brushes are assemblies of one or more polymers with one side tethered to the implant surface, using a preformed polymer with a reactive end group or building up the polymer in situ. Their excellent long-term stability, chemical robustness, biocompatibility, and controllable thickness make them a promising material for bacteria adhesion resistance. Diamond-like carbon, which is an amorphous carbon thin film initially developed to serve as a protective coating in hard drive disks, is another coating material that has recently been adapted for biological applications. These coatings have low friction, high wear resistance, chemical inertness, and optical transparency, while also being economical and have relatively easy synthesis.

A different approach is to develop coatings, which will kill any bacteria that adhere to the surface. ${ }^{168}$ These include Ti-based photoactive coatings, metal-impregnated coatings, implant surfaces modified with antimicrobial peptides, surfaces functionalized with quaternary ammonium salts (disinfectants), and nitric oxide-doped xerogel coatings. Some metal-impregnated antibacterial coatings include copper-sputtered polyester, copper-titania, silver-doped zeolite, Ti-silver coatings, silver-silica thin film, and lanthanum oxide. ${ }^{167}$

Rather than killing bacteria that adheres to the surface, another approach to prevent bacterial adhesion is by killing bacteria before they even come into contact with the implant surface. ${ }^{168}$ This may be achieved by the controlled, time-delayed release of antimicrobial agents from an implant coating through diffusion or convection mechanisms, solvent-mediated activation, or chemical reactions/degradation/erosion. Antibiotic bone cement is a well-known example of using controlled, time-delayed release of antimicrobial agents, while antibiotic-impregnated hydrogel coatings are a more recent development. Hydrogels are cross-linked polymers that swell upon reaction with water, which aid in the controlled release of loaded antibiotics. Vancomycin-PLGA coatings on the surface of Ti substrates have been explored in in vitro and animal studies. ${ }^{169}$ Even after gamma radiation sterilization, the vancomycin still maintained its biological activity and did not lose its effectiveness in in vitro and in vivo characterizations. The antibacterial efficacy of the vancomycin-loaded coating was also evaluated in vivo using a rabbit fracture model. The vancomycin-coated $\mathrm{Ti}$ implants were found to be promising solutions in preventing implant-associated infection, with no active signs of infection after 4 weeks in the animals with vancomycin-coated implants, unlike the presence of pus and necrotic tissue in the control animals.

Chitosan, which is a polysaccharide derived from crustaceans and is composed of D-glucosamine and $\mathrm{N}$-acetylD-glucosamine units, ${ }^{170}$ has also been investigated as an antibiotic-loaded nanoparticulate coating for Ti substrates. It has been found to be effective in inhibiting bacterial growth in in vitro assessments ${ }^{168,170}$ (Figure 3). Chitosan is nontoxic and biocompatible as well as easily degradable in the human body when it comes into contact with lysozyme to form saccharide and glucosamine. ${ }^{168,170}$

Despite the promise shown by coatings to address infection, there is some concern that the routine use of antibiotic-loaded biomaterials may increase the spread of antibiotic resistance. ${ }^{167}$ Furthermore, it is likely that the antibiotic release from laden biomaterials will diminish with time, therefore the ability to provide continuous delivery will require further research for each potential approach. The strength and brittleness of these coatings also need to be considered, particularly those that are not intended to be resorbed, so as to withstand repeated mechanical loading. Therefore, the antimicrobial coating of the future will have to meet these criteria, while still being capable to be manufactured in reasonable volumes.

\section{Bioactive glass}

In the late 1960s and early 1970s, Professor Larry Hench developed a new biocompatible material using silica (glass) as a base material that could be mixed with other materials such as $\mathrm{Ca}$ to treat bone fractures. Professor Hench's 45S5 Bioglass ${ }^{\circledR}$ was the first synthetic material found to chemically bond with bone, which helped launch the field of bioactive ceramics (or bioceramics). ${ }^{171}$ It is composed of sodium oxide, $\mathrm{CaO}$, phosphates, and silicates and has been in clinical use since $1985 .{ }^{172}$ These are minerals that occur naturally in the 

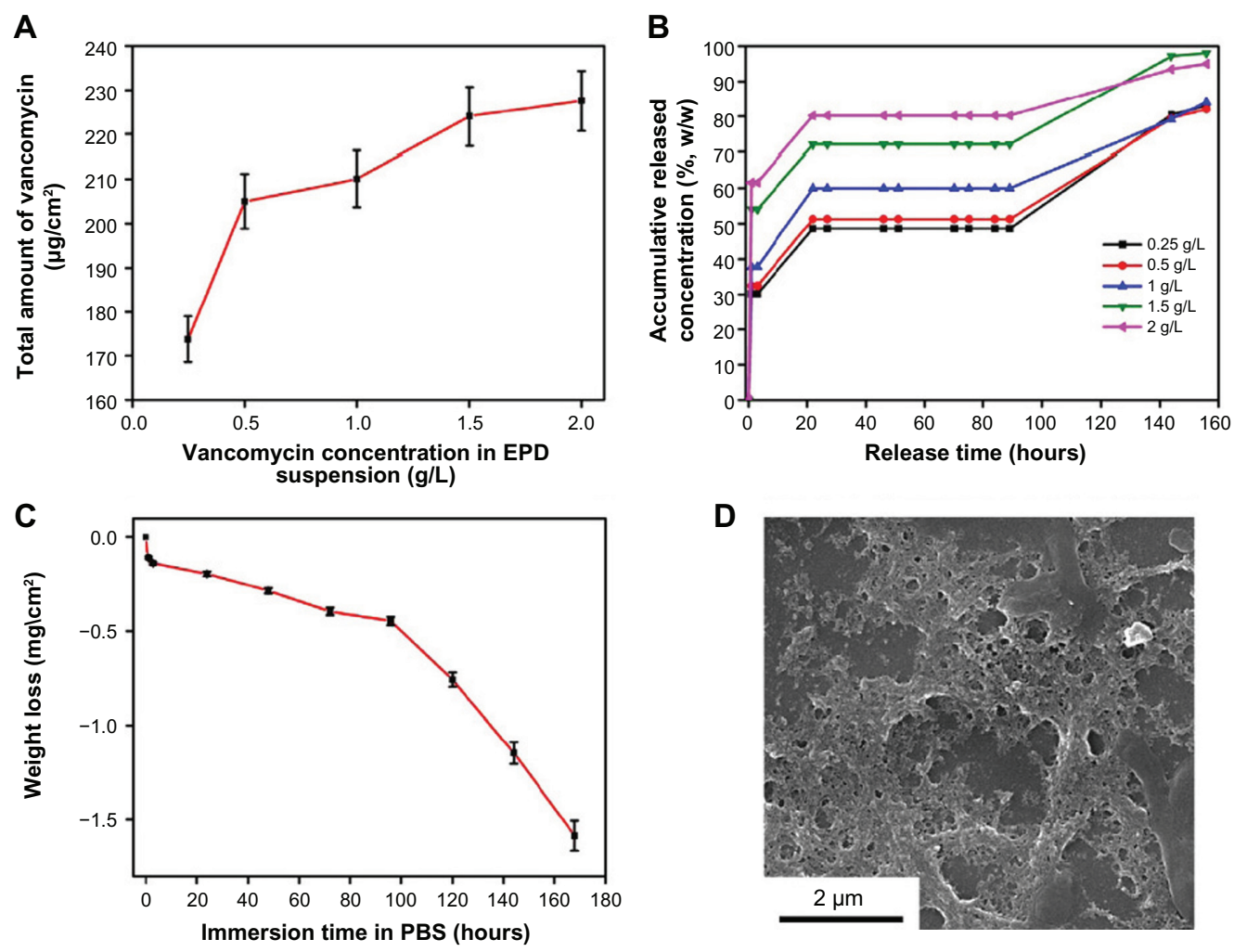

Figure 3 Characteristics of vancomycin-loaded chitosan coating.

Notes: (A) The total amount of drug loaded in the chitosan matrix during fabrication was determined as a function of vancomycin concentration in the suspension. (B) At the early stage, a burst release of vancomycin from the composite coatings was noticed. Afterwards, almost no release was detected for a certain period (approximately 90 hours). At the late stage, gradual release of the glycopeptides antibiotic was observed. (C) Accumulative weight loss of the coatings in PBS solution over time. The amount of chitosan weight loss was relatively noticeable after a long period of incubation ( 90 hours). (D) Surface morphology of chitosan coating after 7 day incubation in the PBS solution at $37^{\circ} \mathrm{C}$. The presence of many pores revealed slow degradation and detachment of the coating in PBS. Reprinted from Mater Sci Eng C Mater Biol Appl, 4 I, Ordikhani F, Tamjid E, Simchi A, Characterization and antibacterial performance of electrodeposited chitosan-vancomycin composite coatings for prevention of implantassociated infections, 240-248, Copyright (C) 2014, with permission from Elsevier. ${ }^{170}$

Abbreviations: EPD, electrophoretic deposition; PBS, phosphate-buffered saline.

body ( $\mathrm{Si}$ dioxide $\left[\mathrm{SiO}_{2}\right], \mathrm{Ca}$, sodium oxide $\left[\mathrm{Na}_{2} \mathrm{O}\right]$, hydrogen $[\mathrm{H}]$, and phosphorous $[\mathrm{P}]$ ), with the molecular proportions of the $\mathrm{Ca}$ and phosphorous oxides being similar to those in bone. Upon exposure to an aqueous solution or body fluids, the surface of a bioactive glass implant converts to a silica$\mathrm{CaO}$ /phosphorous pentoxide $\left(\mathrm{P}_{2} \mathrm{O}_{5}\right)$-rich gel layer that subsequently mineralizes into hydroxycarbonate. This gel layer promotes the differentiation of osteoblasts and deposition of new bone. Released components such as $\mathrm{Ca}^{2+}$ and $\mathrm{PO}_{4}^{3-}$ are known to promote osteoconduction by forming a $\mathrm{CaP}$ layer at the surface. ${ }^{173}$

Bioactive glass has shown good adhesion to stainless steel due to its high thermal expansion and bioactivity. ${ }^{168} \mathrm{Si}$ carbide ( $\mathrm{SiC}$ ) ceramics coated with a bioactive glass layer have also shown excellent osteoconductive properties, while $\mathrm{SiC}$ still being able to provide load-bearing capabilities. In a 4-week rabbit study, bioactive glass coating on commercially pure Ti implants has been found to be highly osteogenic at a distance away from the implants with more pronounced bone formation compared to the immediate vicinity of the implants (Figure 4). ${ }^{173}$

Taking advantage of strontium (Sr)'s established enhancement of bone-forming osteoblast function, Sr-substituted bioactive glass has also been evaluated as a coating on grit-blasted Ti alloy implants. ${ }^{174}$ When compared against control implants coated with HA in a 24-week rabbit model, interpositional fibrous tissue was rarely seen at the bone-implant interface in both implant groups. This study provided a preclinical proof of concept that the strontium-bioactive glass composite is able to combine the beneficial effects of Sr with the osteostimulative potential of bioactive glass dissolution products, and thus may be a significant benefit in reconstructive surgery.

\section{Silicon nitride}

$\mathrm{Si}_{3} \mathrm{~N}_{4}$ is currently being introduced as a biomaterial because it is a hydrophilic negative charged ceramic, which means that blood with nutrients and proteins attach to the material, facilitating bone-cell adherence and incorporation of 
A Before implantation

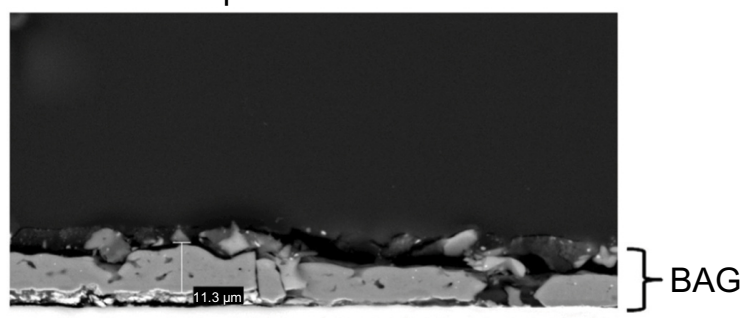

$\mathrm{Ti}$

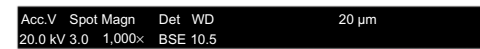

B 2 weeks after implantation

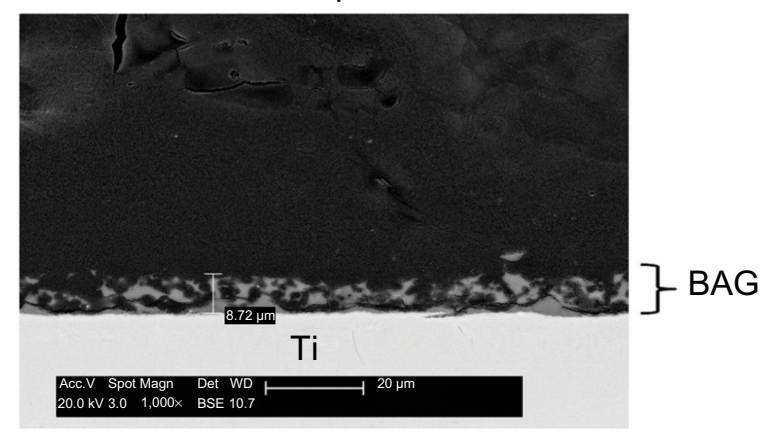

C 4 weeks after implantation

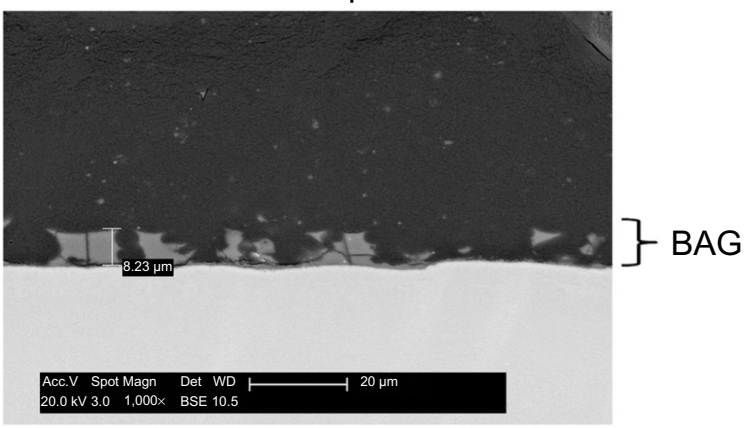

D

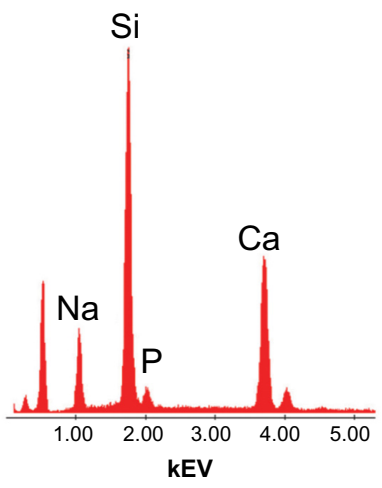

E

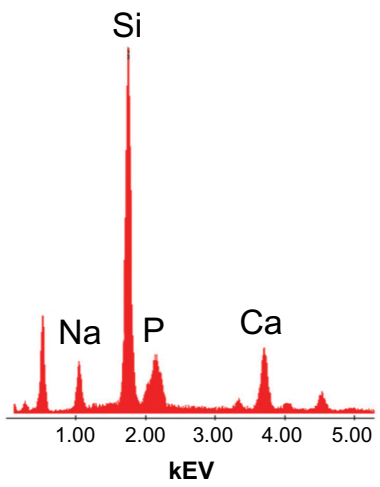

$\mathbf{F}$

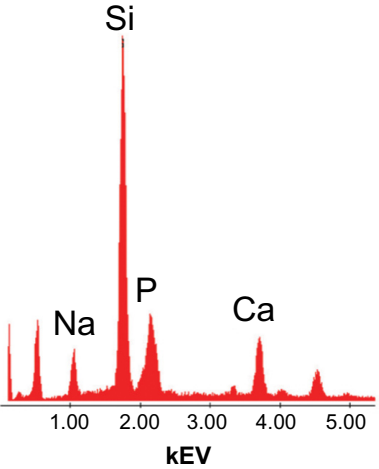

Figure 4 Scanning electron microscope images of a bioactive glass coating at different time-points.

Notes: The approximate thickness of the fabricated bioactive glass coating was $10 \mu \mathrm{m}(\mathbf{A})$. The coating almost retained its thickness after 2 and 4 weeks of implantation (B and C). But, the images also indicate dissolution of the coating after the healing periods. The EDS analysis (D-F) showed the presence of Ca and P (ie, consistent with calcium phosphate) in the coating even after 4 weeks of implantation. D-F are the EDS spectra corresponding to A (before implantation), B (2 weeks after implantation), and $\mathbf{C}$ ( 4 weeks after implantation), respectively. Reproduced from Chaudhari A, Braem A, Vleugels J, et al. Bone tissue response to porous and functionalized titanium and silica based coatings. PLoS One. 20I I;6(9):e24I86. ${ }^{173}$

Abbreviations: Acc, accelerating; BAG, bioactive glass; BSE, backscatter electrons; Det, detector; EDS, energy-dispersive X-ray spectroscopy; Magn, magnification; WD, working distance.

the material in the surrounding bone. ${ }^{175}$ Recently, $\mathrm{Si}_{3} \mathrm{~N}_{4}$ has been evaluated as an alternative to existing coated implants. A porous form of $\mathrm{Si}_{3} \mathrm{~N}_{4}$, cancellous-structured ceramic, has been developed as a nonresorbable, partially radiolucent porous structure that can be bonded to orthopedic implants made of $\mathrm{Si}_{3} \mathrm{~N}_{4}$ to facilitate skeletal attachment. ${ }^{176}$ Bone ingrowth into the porous structure was shown as a viable method for achieving skeletal attachment in a sheep model. ${ }^{176}$ A clinical trial of $\mathrm{Si}_{3} \mathrm{~N}_{4}$ implants has also been investigated in patients undergoing anterior cervical discectomy with interbody fusions. ${ }^{175}$ According to the $\mathrm{Si}_{3} \mathrm{~N}_{4}$ implant manufacturer, ${ }^{177}$ the incidence of cervical spine fusion was found to be equivalent between patients implanted with porous $\mathrm{Si}_{3} \mathrm{~N}_{4}$ implants with no bone or bone fillers and those who had PEEK implants with bone autograft. The anti-infective and osseointegration properties of $\mathrm{Si}_{3} \mathrm{~N}_{4}$ implants have also been demonstrated in the treatment of calvarial defects using a rat model. ${ }^{178}$ The $\mathrm{Si}_{3} \mathrm{~N}_{4}$ implants demonstrated improved new bone formation at 3 months compared to PEEK and Ti implants, both in the absence [69\% vs 24\% (PEEK) and 36\% 
(Ti)] and presence [41\% vs 21\% (PEEK) and 26\% (Ti)] of Staphylococcus epidermidis. No live bacteria was present adjacent to the $\mathrm{Si}_{3} \mathrm{~N}_{4}$ implants, demonstrating its resistance to bacterial infection, compared to live bacteria identified around $88 \%$ of PEEK implants and $21 \%$ of Ti implants.

\section{lodine}

To reduce the risk of infections, several biomaterial surface treatments, such as iodine coatings, have been proposed. It is believed that iodine-containing surfaces may have antibacterial activity, biocompatibility, and no cytotoxicity. ${ }^{179}$ Iodine-supported Ti implants have been compared against stainless steel and Ti implants serving as controls in a rabbit femora study. ${ }^{180}$ Fewer signs of infection and inflammatory changes were observed in conjunction with the iodine-support Ti implants in the presence of Staphylococcus aureus or Escherichia coli. Bone formation was also observed around the iodine-supported Ti and Ti implants, while little osteoid formation was found around the stainless steel implants.

The efficacy of iodine-supported Ti implants has also been shown in the management of patients with active infection (Figure 5). ${ }^{179,181-183}$ Patients with pyogenic vertebral osteomyelitis were operated on using Ti spinal instrumentation with iodine-containing surfaces. ${ }^{181}$ The infection subsided in all 14 patients, with both white blood cell count and C-reactive protein levels returning to normal ranges by the final follow-up. Iodine-coated megaprostheses have also been used in a clinical trial to treat patients with malignant bone tumor or pyrogenic arthritis. ${ }^{182}$ In all cases, there were no signs of infection at the time of the last follow-up. Osseointegration was found around iodine-supported megaprostheses with no evidence of loosening. These iodine-supported implants showed promise for the prevention and treatment of infections, even in the presence of large bone defects.

\section{Bone graft material}

Due to the increasing use of bone grafts and the challenges with biological grafts, synthetic bone graft substitutes are expected to play a vital role in bone regeneration. It has been stated that approximately $60 \%$ of the currently available synthetic bone graft substitutes incorporate some form of ceramics, such as Ca sulfates, HA, TCP, or combinations thereof. ${ }^{184}$ Recent developments in bone substitutes have explored the use of antibacterials or BMPs. On the other hand, limited indications for synthetic bone grafts, along with the drawbacks and potential complications related to the use of allo- and autograft, have facilitated the progress toward a biologic alternative.

\section{Bioactive glass}

Because bioactive glass is available in multiple forms such as particulate, pellets, powder, mesh, and cones, it can be used for different applications. Bioactive glasses are composed of $\mathrm{SiO}_{2}$, sodium oxide $\left(\mathrm{Na}_{2} \mathrm{O}\right), \mathrm{CaO}$, and

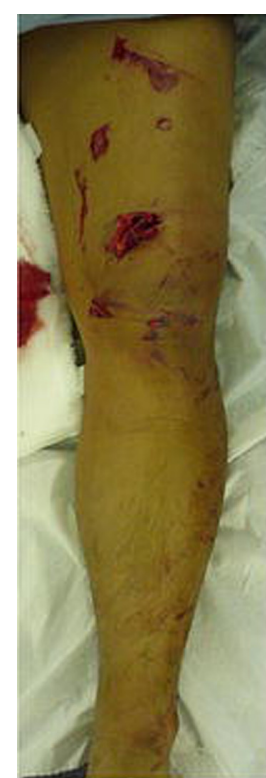

A

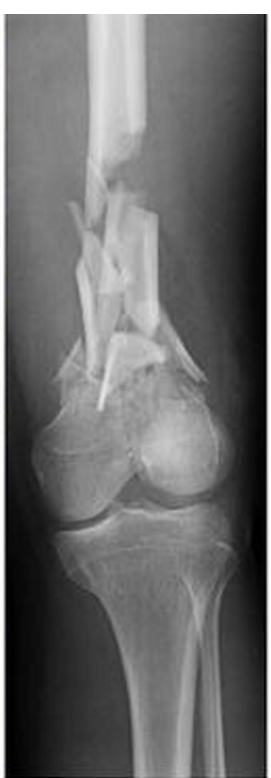

B

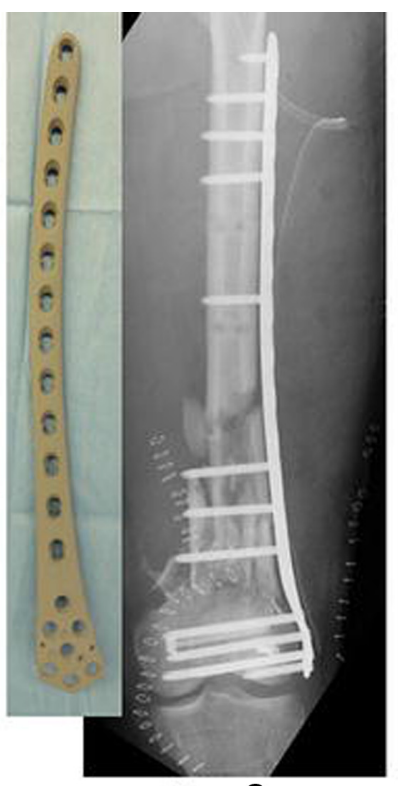

C

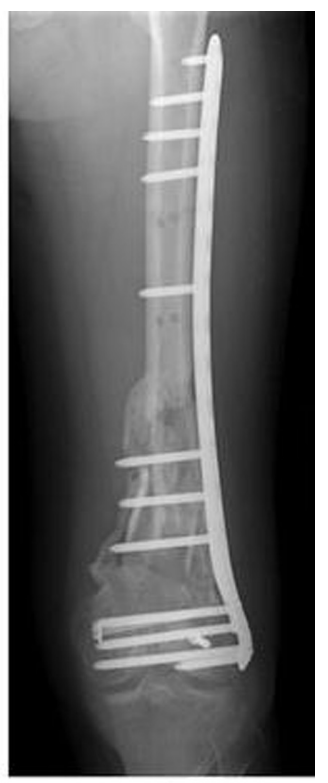

D

Figure 5 Case of a 42 year-old patient who was treated with an iodine-coated internal fixation plate.

Notes: A Gustilo grade Illa open fracture (A: photograph; B: X-ray) treated with an iodine-supported titanium plate (C). Bony union was established with good callus formation at 4 months postsurgery, with no signs of infection (D). Reproduced from Tsuchiya H, Shirai T, Nishida H, et al. Innovative antimicrobial coating of titanium implants with iodine. J Orthop Sci. 2012;17(5):595-604. ${ }^{183}$ 
phosphorous pentoxide $\left(\mathrm{P}_{2} \mathrm{O}_{5}\right)$. By varying the proportions of sodium oxide, $\mathrm{CaO}$, and $\mathrm{Si}$ dioxide, a range of forms from soluble to nonresorbable ones can be prepared. ${ }^{184}$ Bioactive glass has been observed to bond with certain connective tissue through collagen formation with the glass surface. However, the low fracture resistance of glass material makes it more useful in load-free areas. Thus, bioactive glass has been used in particle form to fill periodontal osseous defects in humans. ${ }^{185}$ Although it has relatively low mechanical strength and decreased fracture resistance, altering its composition may allow more widespread use in low load-bearing areas. Bioactive glass is a versatile replacement material, as it is available in multiple forms and also can be molded into desired forms.

Sr- and zinc-doped bioactive glasses have also emerged as materials of particular interest, as there is increasing evidence that these ions may control bone formation in both healthy individuals and those with metabolically compromised tissues. ${ }^{186}$ $\mathrm{Sr}$ can enhance osteoblastic proliferation and decrease osteoclastic turnover ${ }^{187}$ while zinc provides enhanced antibacterial efficacy and is linked with improved bone quality. Sr/zincbased silicate glasses have been shown to react appropriately in metabolically compromised tissue using a rat model, thus demonstrating their potential as bone graft materials. ${ }^{188}$

\section{Ceramic products}

\section{Calcium phosphate}

$\mathrm{CaP}$ ceramics have been used for several decades due to their excellent biocompatibility, bioactivity, osteoconductivity, and mechanical strength. ${ }^{189} \mathrm{~A}$ limitation with current $\mathrm{CaP}$ bone graft materials is that they exist in large granular form, which affects its handling ability during surgery. To improve handling ability and to better fill defects of complex geometric shapes, injectable and moldable forms of bone substitute material have been developed recently. An ovine critical-sized femoral condyle defect model has examined the use of silicate-substituted $\mathrm{CaP}$ bone substitute materials with various granule sizes. ${ }^{190}$ Smaller granules were found to induce more bone formation, but may be associated with more fragmentation. Therefore, an optimal particle size may exist. This study also shows why interest in doping $\mathrm{CaP}$ graft material with silicate has emerged, because Si has been theorized to trigger faster bone formation. Si has been shown to occur in higher concentrations in the early stages of the calcification of young bone than in mature bone. ${ }^{191}$

\section{Collagen-HA}

Collagen-HA scaffolds are composed of collagen and HA, which are the two main constituents of bone, making it biocompatible, osteoconductive, osteoinductive, and bioabsorbable, with nontoxic degradation products. ${ }^{192}$ The combination of these materials also helps offset the limitations in each standalone material. ${ }^{193}$ For example, the ductile properties of collagen help to increase the relatively poorer fracture toughness of HA. The addition of collagen to a ceramic structure can also provide other advantages such as shape control and increased particle and defect wall adhesion. Collagen-HA scaffolds have been found to be potentially suitable for a load-bearing defect based on the comparable healing to the current gold standard of autogenous bone graft after 4 months in a rabbit radius osteotomy defect model. ${ }^{192}$ The collagen-HA scaffold may also serve as an ideal carrier for low-dose recombinant human BMP-2 retention to promote faster healing. At the present time, further clinical studies are required to validate its effectiveness.

\section{Calcium sulfate}

The primary features of Ca sulfate are its biocompatibility, rapid resorption rate, and unique ability to stimulate osteogenesis. ${ }^{194}$ In a prospective study of 15 patients with benign bone lesions and chronic osteomyelitis, whose osseous defects were filled with $\mathrm{Ca}$ sulfate, 13 cases showed Ca sulfate resorption and new bone incorporation. To address the slow resorption rate of $\mathrm{HA}$, faster resorbing materials such as Ca sulfate have been combined with HA. ${ }^{195}$ The resorbing $\mathrm{Ca}$ sulfate material will leave space for the bone tissue to grow into and the osteoconductive HA material will guide the bone cells to grow in and onto the bone graft material. Good clinical outcomes of $\mathrm{Ca}$ sulfate and HA mixtures have been reported in various applications. Biphasic bone substitute consisting of a mixture of $\mathrm{Ca}$ sulfate and HA was used on 15 consecutive patients who had a malunion after a distal radius fracture. ${ }^{196}$ The bone substitute was found to be replaced by bone, but a minor loss of the achieved radiographic correction was noted in some patients during osteotomy healing, which was believed to be related to the lack of rigidity of the implant fixation system. These calcium sulfate and HA mixtures have also been used as bone grafting material in patients with aneurysmal bone cysts and giant cell tumors of the knee. ${ }^{197}$ All patients regained close to normal function, and the composite graft material was noted to appear to be an effective alternative to autologous cancellous bone graft in the treatment of large osteolytic lesions in periarticular areas around the knee joint. However, some concerns have been raised about the radiopaque appearance of the bone graft substitute, which may potentially interfere with the early detection of tumor recurrence. 


\section{Porous Ti particles}

It is believed that porous Ti possess mechanical characteristics favorable for impaction grafting, such as good handling, impactability, and resistance to compressive loading. ${ }^{198}$ Porous Ti particles coated with either silicated $\mathrm{CaP}$ consisting of a sol-gel coating of HA and TCP crystals (HA:TCP ratio of 60:40) embedded in a silica layer or a coating consisting of carbonated apatite have been examined in an unloaded goat model. ${ }^{198}$ The osteoconductive properties of impacted porous $\mathrm{Ti}$ with a $\mathrm{CaP}$ coating have been shown to be comparable to impacted allograft bone and impacted biphasic ceramics. Under loaded conditions, CaP-coated porous Ti particles have also been evaluated in goats to reconstruct AAOS type-III defects in the acetabulum. ${ }^{199} \mathrm{By}$ 4 weeks postimplantation, new bone was found to penetrate throughout the whole depth of the graft layer, both through the larger interparticle pores and through the smaller-sized intraparticle pores. No Ti microparticles or macrophageor osteoclast-induced osteolysis was observed. The study showed that porous Ti has promise for cemented impaction grafting.

\section{D printing}

Although much of the focus of bone graft material research has been on identifying novel source materials, the increasing popularity and interest in additive manufacturing techniques has also helped to spur the development of synthetic bone grafts. Novel bone graft materials that can be synthesized using these techniques may help narrow down options for graft materials that are easier to fabricate. Additive manufacturing or rapid prototyping is a broad term that includes $3 \mathrm{D}$ printing and other techniques that rely on computer-based layer-by-layer stacking to shape a 3D physical structure. Additive manufacturing has gained interest to the extent that the processes have been standardized and classified by the American Society for Testing and Materials.

In that regard, bone graft materials that are in the form of powders, such as biphasic $\mathrm{CaP}$, make them desirable for fabrication using $3 \mathrm{D}$ printing. ${ }^{200}$ In particular, the reconstruction of complex bone defects can benefit from the use of freely moldable materials that enable the synthesis of patient-specific implants. 3D-printed samples are characterized by a high microporosity (above $30 \mathrm{vol} \%$ ), ${ }^{200}$ which is an important characteristic for bone generation. Porous scaffolds can be produced by printing a mold with wax, infiltrating it with the ceramic slurry, and then burning out the negative matrix material. Scaffolds can also be prepared from spray-dried granules of the graft material, containing polymeric additives as a binder.
Additive manufacturing techniques also result in minimal waste of biomaterial and make these processes suitable for mass production of tissue-engineering structures. ${ }^{201}$ Different types of medical devices, such as prosthetic sockets, that are customized to individual patients have been fabricated using 3D-printing techniques, ${ }^{202,203}$ however, questions regarding the strength and durability of printed prosthetic sockets have been raised. ${ }^{202}$ The technology has more recently been advanced to allow the delivery of anti-infective and chemotherapeutic drugs from 3D-printed constructs. For example, 3D-printed PLA constructs loaded with gentamycin and methotrexate were shown to have antibacterial effects and to reduce the proliferation of osteosarcoma cells in cell culture and assay experiments. ${ }^{204}$ This may open the door to fabrication of patient-specific treatment constructs for personalized medicine.

However, there are some barriers to widespread commercial use of additive manufacturing, such as $3 \mathrm{D}$ printing. For these fabrication methods to provide effective grafts, they need to be able to have functioning vascular networks penetrate the graft. This may be overcome by providing pores within the printed structure, so as to provide adequate nutrient and gaseous exchange for the tissue. There has also been some concern that incorporating cell delivery into piezoelectric printing techniques may affect long-term cell viability and result in cell lysis. Thus, growth factors and cells may likely need to be applied intraoperatively, rather than as part of the printing process. Furthermore, the regulatory environment regarding additive manufacturing-based products may not be quite as apparent.

\section{Conclusion}

There continues to be great interest in developing new biomaterials for orthopedic implants, using either novel materials, altering the formulations of existing materials, or finding new applications for existing materials. Despite the effective clinical performance of contemporary orthopedic implants, with the expected growth in the use of orthopedic implants and increasing demands placed on the devices by the patients, improving the performance of the devices through the use of "new" biomaterials may aid in addressing these needs. The ability to translate in vitro evaluations, animal studies, and pilot clinical studies to larger scale use will help determine the viability of many of these biomaterials from a safety and effectiveness standpoint, but also from a commercial standpoint in terms of being able to produce these biomaterials on a large scale and in a cost effective manner. 


\section{Disclosure}

$\mathrm{KLO}$, BMY, and JBW received no funding for this work. KLO is an employee and shareholder of Exponent, a scientific and engineering consulting firm. Exponent has been paid fees by entities in the biomedical arena for the consulting services (Ferring Pharmaceuticals, Inc., Stryker Orthopaedics, Biomet, Paradigm Spine, Pacira Pharmaceuticals, Medtronic, Stryker Mako Surgical) and litigation services (Zimmer, Ethicon) of KLO. BMY is an employee of Exponent. JBW is an employee and shareholder of Exponent. Exponent has been paid fees by entities in the biomedical arena for the consulting services of BMY and JBW. The authors report no other conflicts of interest in this work.

\section{References}

1. Kurtz SM, Devine JN. PEEK biomaterials in trauma, orthopedic, and spinal implants. Biomaterials. 2007;28(32):4845-4869.

2. Brown SA, Hastings RS, Mason JJ, et al. Characterization of short-fibre reinforced thermoplastics for fracture fixation devices. Biomaterials. 1990;11(8):541-547.

3. Skinner HB. Composite technology for total hip arthroplasty. Clin Orthop Relat Res. 1988;235:224-236.

4. Williams D, McNamara A, Turner R. Potential of polyetheretherketone (PEEK) and carbon-fibre-reinforced PEEK in medical applications. J Mater Sci Lett. 1987;6(2):188-190.

5. Scotchford CA, Garle MJ, Batchelor J, et al. Use of a novel carbon fibre composite material for the femoral stem component of a THR system: in vitro biological assessment. Biomaterials. 2003;24(26):4871-4879.

6. Wenz LM, Merritt K, Brown SA, et al. In vitro biocompatibility of polyetheretherketone and polysulfone composites. J Biomed Mater Res. 1990;24(2):207-215.

7. Jockisch K, Brown S, Bauer T, et al. Biological response to choppedcarbon-fiber-reinforced peek. J Biomed Mater Res. 1992;26(2): 133-146.

8. Bakar MA, Cheang P, Khor K. Mechanical properties of injection molded hydroxyapatite-polyetheretherketone biocomposites. Compos Sci Technol. 2003;63(3):421-425.

9. Fan JP, Tsui CP, Tang CY, et al. Influence of interphase layer on the overall elasto-plastic behaviors of HA/PEEK biocomposite. Biomaterials. 2004;25(23):5363-5373.

10. Petrovic L, Pohle D, Munstedt H, et al. Effect of betaTCP filled polyetheretherketone on osteoblast cell proliferation in vitro. J Biomed Sci. 2006;13(1):41-46.

11. Yu S, Hariram KP, Kumar R, et al. In vitro apatite formation and its growth kinetics on hydroxyapatite/polyetheretherketone biocomposites. Biomaterials. 2005;26(15):2343-2352.

12. Bakar MA, Cheng M, Tang S, et al. Tensile properties, tension-tension fatigue and biological response of polyetheretherketone-hydroxyapatite composites for load-bearing orthopedic implants. Biomaterials. 2003;24(13):2245-2250.

13. Kyomoto M, Moro T, Yamane S, et al. Smart PEEK modified by selfinitiated surface graft polymerization for orthopedic bearings. Reconstr Rev. 2014;4(3):36-45.

14. Steinberg EL, Rath E, Shlaifer A, et al. Carbon fiber reinforced PEEK Optima - a composite material biomechanical properties and wear/ debris characteristics of CF-PEEK composites for orthopedic trauma implants. J Mech Behav Biomed Mater. 2013;17:221-228.

15. Nakahara I, Takao M, Bandoh $\mathrm{S}$, et al. In vivo implant fixation of carbon fiber-reinforced PEEK hip prostheses in an ovine model. J Orthop Res. 2013;31(3):485-492.
16. Rotini R, Cavaciocchi M, Fabbri D, et al. Proximal humeral fracture fixation: multicenter study with carbon fiber peek plate. Musculoskelet Surg. Epub 2015 May 12.

17. Kurtz SM, Siskey R, Reitman M. Accelerated aging, natural aging, and small punch testing of gamma-air sterilized polycarbonate urethane acetabular components. J Biomed Mater Res B Appl Biomater. 2010;93(2):442-447.

18. Carbone A, Howie DW, McGee M, et al. Aging performance of a compliant layer bearing acetabular prosthesis in an ovine hip arthroplasty model. J Arthroplasty. 2006;21(6):899-906.

19. Khan I, Smith N, Jones E, et al. Analysis and evaluation of a biomedical polycarbonate urethane tested in an in vitro study and an ovine arthroplasty model. Part II: in vivo investigation. Biomaterials. 2005;26(6):633-643.

20. Scholes SC, Unsworth A, Jones E. Polyurethane unicondylar knee prostheses: simulator wear tests and lubrication studies. Phys Med Biol. 2007;52(1):197-212.

21. John KR. The use of compliant layer prosthetic components in orthopedic joint repair and replacement: a review. J Biomed Mater Res Part B 2014;102(6):1332-1341.

22. John KS, Gupta M. Evaluation of the wear performance of a polycarbonate-urethane acetabular component in a hip joint simulator and comparison with UHMWPE and cross-linked UHMWPE. J Biomater Appl. 2012;27(1):55-65.

23. Elsner JJ, Shemesh M, Mezape Y, et al. Long-term evaluation of a compliant cushion form acetabular bearing for hip joint replacement: a 20 million cycles wear simulation. J Orthop Res. 2011;29(12):1859-1866.

24. Smith RA, Hallab NJ. In vitro macrophage response to polyethylene and polycarbonate-urethane particles. J Biomed Mater Res A. 2010; 93(1):347-355.

25. Moroni A, Nocco E, Hoque M, et al. Cushion bearings versus large diameter head metal-on-metal bearings in total hip arthroplasty: a short-term metal ion study. Arch Orthop Trauma Surg. 2012;132(1):123-129.

26. Siebert WE, Mai S, Moroni A, et al. A two-year prospective and retrospective multi-center study of the tribofit(R) hip system. J Long Term Eff Med Implants. 2009;19(2):149-155.

27. Colas A, Curtis J. Silicone biomaterials: history and chemistry. Biomater Sci. 2004;2:80-85.

28. Swanson AB. Silicone rubber implants for replacement of arthritic or destroyed joints in the hand. 1968. Clin Orthop Relat Res. 1997;342: 4-10.

29. Bales JG, Wall LB, Stern PJ. Long-term results of swanson silicone arthroplasty for proximal interphalangeal joint osteoarthritis. J Hand Surg. 2014;39(3):455-461.

30. Chung KC, Burns PB, Kim HM, et al. Long-term followup for rheumatoid arthritis patients in a multicenter outcomes study of silicone metacarpophalangeal joint arthroplasty. Arthritis Care Res. 2012;64(9):1292-1300.

31. Waljee JF, Chung KC. Objective functional outcomes and patient satisfaction after silicone metacarpophalangeal arthroplasty for rheumatoid arthritis. J Hand Surg. 2012;37(1):47-54.

32. Bal BS, Khandkar A, Lakshminarayanan R, et al. Testing of silicon nitride ceramic bearings for total hip arthroplasty. J Biomed Mater Res B Appl Biomater. 2008;87(2):447-454.

33. Bal BS, Khandkar A, Lakshminarayanan R, et al. Fabrication and testing of silicon nitride bearings in total hip arthroplasty: winner of the 2007 "HAP” PAUL award. J Arthroplasty. 2009;24(1):110-116.

34. Mazzocchi M, Bellosi A. On the possibility of silicon nitride as a ceramic for structural orthopaedic implants. Part I: processing, microstructure, mechanical properties, cytotoxicity. J Mater Sci Mater Med. 2008;19(8):2881-2887.

35. Mazzocchi M, Gardini D, Traverso PL, et al. On the possibility of silicon nitride as a ceramic for structural orthopaedic implants. Part II: chemical stability and wear resistance in body environment. J Mater Sci Mater Med. 2008;19(8):2889-2901.

36. Sonntag R, Reinders J, Kretzer JP. What's next? Alternative materials for articulation in total joint replacement. Acta Biomater. 2012;8(7):2434-2441 
37. Klemm H. Silicon nitride for high-temperature applications. JAm Ceram Soc. 2010;93(6):1501-1522.

38. Rahaman MN, Yao A, Bal BS, et al. Ceramics for prosthetic hip and knee joint replacement. J Am Ceram Soc. 2007;90(7):1965-1988.

39. Mittal R, Morley J, Dinopoulos H, et al. Use of bio-resorbable implants for stabilisation of distal radius fractures: the United Kingdom patients' perspective. Injury. 2005;36(2):333-338.

40. Kulkarni R, Pani K, Neuman C, et al. Polylactic acid for surgical implants. Arch Surg. 1966;93(5):839-843.

41. Savage K, Sardar ZM, Pohjonen T, et al. Mechanical properties of bioresorbable self-reinforced posterior cervical rods. J Spinal Disord Tech. 2014;27(2):E66-E71.

42. Al-Sukhun J, Törnwall J, Lindqvist C, et al. Bioresorbable poly-L/ DL-lactide (P [L/DL] LA 70/30) plates are reliable for repairing large inferior orbital wall bony defects: a pilot study. J Oral Maxillofac Surg. 2006;64(1):47-55.

43. Barber FA. Poly-D, L-lactide interference screws for anterior cruciate ligament reconstruction. Arthroscopy. 2005;21(7):804-808.

44. Ashammakhi N, Suuronen R, Tiainen J, et al. Spotlight on naturally absorbable osteofixation devices. J Craniofac Surg. 2003;14(2): $247-259$.

45. Enislidis G, Yerit K, Wittwer G, et al. Self-reinforced biodegradable plates and screws for fixation of zygomatic fractures. J Craniomaxillofac Surg. 2005;33(2):95-102.

46. Frost A, Bagouri E, Brown M, et al. Osteolysis following resorbable poly-L-lactide-co-D, L-lactide PLIF cage use: a review of cases. Eur Spine J. 2012;21(3):449-454.

47. Cox CL, Spindler KP, Leonard JP, et al. Do newer-generation bioabsorbable screws become incorporated into bone at two years after ACL reconstruction with patellar tendon graft?: a cohort study. J Bone Joint Surg Am. 2014;96(3):244-250.

48. Böstman OM, Pihlajamäki HK. Adverse tissue reactions to bioabsorbable fixation devices. Clin Orthop Related Res. 2000;371: 216-227.

49. Kontakis GM, Pagkalos JE, Tosounidis TI, et al. Bioabsorbable materials in orthopaedics. Acta Orthop Belg. 2007;73(2):159.

50. Bassuener SR, Mullis BH, Harrison RK, et al. Use of bioabsorbable pins in surgical fixation of comminuted periarticular fractures. J Orthop Trauma. 2012;26(10):607-610.

51. Dawson PH, O'Briain DE, Connolly PJ, et al. Bioabsorbable pins for bone fixation in the less invasive innominate osteotomy. $J$ Pediatr Orthop B. 2014;23(5):426-429.

52. Daentzer D, Floerkemeier T, Bartsch I, et al. Preliminary results in anterior cervical discectomy and fusion with an experimental bioabsorbable cage - clinical and radiological findings in an ovine animal model. Springerplus. 2013;2(1):1-8.

53. Kobayashi S, Yamaji S. Effect of hydrolysis on mechanical behavior of bioabsorbable composites. Mater Sci Forum. 2014;783:1274-1279.

54. Cao L, Duan P-G, Li X-L, et al. Biomechanical stability of a bioabsorbable self-retaining polylactic acid/nano-sized $\beta$-tricalcium phosphate cervical spine interbody fusion device in single-level anterior cervical discectomy and fusion sheep models. Int J Nanomed. 2012;7:5875.

55. Adamus A, Jozwiakowska J, Wach R, et al. In vitro degradation of $\beta$-Tricalcium phosphate reinforced poly (L-Lactic Acid). Mater Sci Forum. 2012;714:283-290.

56. Ntagiopoulos PG, Demey G, Tavernier T, et al. Comparison of resorption and remodeling of bioabsorbable interference screws in anterior cruciate ligament reconstruction. Int Orthop. 2015;39(4): 697-706.

57. Moreira Teixeira L, Patterson J, Luyten F. Skeletal tissue regeneration: where can hydrogels play a role? Int Orthop. 2014;38(9): 1861-1876.

58. Navarro M, Michiardi A, Castaño O, et al. Biomaterials in orthopaedics. $J$ R Soc Interface. 2008;5(27):1137-1158.

59. Wolf MT, Dearth CL, Sonnenberg SB, et al. Naturally derived and synthetic scaffolds for skeletal muscle reconstruction. Adv Drug Deliv Rev. 2015;84:208-221.
60. Holzwarth JM, Ma PX. Biomimetic nanofibrous scaffolds for bone tissue engineering. Biomaterials. 2011;32(36):9622-9629.

61. Bose S, Roy M, Bandyopadhyay A. Recent advances in bone tissue engineering scaffolds. Trends Biotechnol. 2012;30(10):546-554.

62. Guarino V, Causa F, Ambrosio L. Bioactive scaffolds for bone and ligament tissue. Expert Rev Med Devices. 2007;4(3):405-418.

63. Cao Z, Dou C, Dong S. Scaffolding biomaterials for cartilage regeneration. J Nanomater. 2014;2014:8.

64. Cancedda R, Dozin B, Giannoni P, et al. Tissue engineering and cell therapy of cartilage and bone. Matrix Biol. 2003;22(1):81-91.

65. Revell PA, Damien E, Di Silvio L, et al. Tissue engineered intervertebral disc repair in the pig using injectable polymers. JMater Sci Mater Med. 2007;18(2):303-308.

66. Khan AF, Saleem M, Afzal A, et al. Bioactive behavior of silicon substituted calcium phosphate based bioceramics for bone regeneration. Mater Sci Eng C. 2014;35:245-252.

67. Patel N, Best SM, Bonfield W, et al. A comparative study on the in vivo behavior of hydroxyapatite and silicon substituted hydroxyapatite granules. J Mater Sci Mater Med. 2002;13(12):1199-1206.

68. Botelho CM, Brooks RA, Best SM, et al. Human osteoblast response to silicon-substituted hydroxyapatite. J Biomed Mater Res A. 2006;79(3):723-730.

69. Botelho CM, Brooks RA, Spence G, et al. Differentiation of mononuclear precursors into osteoclasts on the surface of Si-substituted hydroxyapatite. J Biomed Mater Res A. 2006;78(4):709-720.

70. Honda M, Kikushima K, Kawanobe Y, et al. Enhanced early osteogenic differentiation by silicon-substituted hydroxyapatite ceramics fabricated via ultrasonic spray pyrolysis route. J Mater Sci Mater Med. 2012;23(12):2923-2932.

71. Hayakawa S, Kanaya T, Tsuru K, et al. Heterogeneous structure and in vitro degradation behavior of wet-chemically derived nanocrystalline silicon-containing hydroxyapatite particles. Acta Biomater. 2013;9(1):4856-4867.

72. Lehmann G, Cacciotti I, Palmero P, et al. Differentiation of osteoblast and osteoclast precursors on pure and silicon-substituted synthesized hydroxyapatites. Biomed Mater. 2012;7(5):055001.

73. Lerner T, Liljenqvist U. Silicate-substituted calcium phosphate as a bone graft substitute in surgery for adolescent idiopathic scoliosis. Eur Spine J. 2013;22(Suppl 2):S185-S194.

74. Mostafa N, Shaltout A, Radev L, et al. In vitro surface biocompatibility of high-content silicon-substituted calcium phosphate ceramics. Cent Eur J Chem. 2013;11(2):140-150.

75. Nagineni VV, James AR, Alimi M, et al. Silicate-substituted calcium phosphate ceramic bone graft replacement for spinal fusion procedures. Spine (Phila Pa 1976). 2012;37(20):E1264-E1272.

76. Surmeneva MA, Surmenev RA, Pichugin VF, et al. In-vitro investigation of magnetron-sputtered coatings based on silicon-substituted hydroxyapatite. J Surf Invest. 2011;5(6):1202-1207.

77. Papadimitropoulos A, Mastrogiacomo M, Peyrin F, et al. Kinetics of in vivo bone deposition by bone marrow stromal cells within a resorbable porous calcium phosphate scaffold: an X-ray computed microtomography study. Biotechnol Bioeng. 2007;98(1):271-281.

78. Naito H, Dohi Y, Zimmermann WH, et al. The effect of mesenchymal stem cell osteoblastic differentiation on the mechanical properties of engineered bone-like tissue. Tissue Eng Part A. 2011;17(17-18): 2321-2329.

79. Thein-Han W, Xu HH. Collagen-calcium phosphate cement scaffolds seeded with umbilical cord stem cells for bone tissue engineering. Tissue Eng Part A. 2011;17(23-24):2943-2454.

80. Koob S, Torio-Padron N, Stark GB, et al. Bone formation and neovascularization mediated by mesenchymal stem cells and endothelial cells in critical-sized calvarial defects. Tissue Eng Part A. 2011;17(3-4): 311-321.

81. Li J, Hong J, Zheng Q, et al. Repair of rat cranial bone defects with nHAC/PLLA and BMP-2-related peptide or rhBMP-2. J Orthop Res. 2011;29(11):1745-1752.

82. Wernike E, Montjovent MO, Liu Y, et al. VEGF incorporated into calcium phosphate ceramics promotes vascularisation and bone formation in vivo. Eur Cell Mater. 2010;19:30-40. 
83. Kempen DH, Lu L, Heijink A, et al. Effect of local sequential VEGF and BMP-2 delivery on ectopic and orthotopic bone regeneration. Biomaterials. 2009;30(14):2816-2825.

84. Patel ZS, Young S, Tabata Y, et al. Dual delivery of an angiogenic and an osteogenic growth factor for bone regeneration in a critical size defect model. Bone. 2008;43(5):931-940.

85. Young S, Patel ZS, Kretlow JD, et al. Dose effect of dual delivery of vascular endothelial growth factor and bone morphogenetic protein-2 on bone regeneration in a rat critical-size defect model. Tissue Eng Part A. 2009;15(9):2347-2362.

86. Kuo YC, Wang CC. Surface modification with peptide for enhancing chondrocyte adhesion and cartilage regeneration in porous scaffolds. Colloids Surf B Biointerfaces. 2011;84(1):63-70.

87. Kuo YC, Wang CC. Cartilage regeneration by culturing chondrocytes in scaffolds grafted with TATVHL peptide. Colloids Surf B Biointerfaces 2012;93:235-240.

88. Shao Z, Zhang X, Pi Y, et al. Polycaprolactone electrospun mesh conjugated with an MSC affinity peptide for MSC homing in vivo. Biomaterials. 2012;33(12):3375-3387.

89. Jayabalan P, Tan AR, Rahaman MN, et al. Bioactive glass 13-93 as a subchondral substrate for tissue-engineered osteochondral constructs: a pilot study. Clin Orthop Relat Res. 2011;469(10):2754-2763.

90. Wu J, Xue K, Li H, et al. Improvement of PHBV scaffolds with bioglass for cartilage tissue engineering. PLoS One. 2013;8(8):e71563.

91. Chang NJ, Jhung YR, Yao CK, et al. Hydrophilic gelatin and hyaluronic acid-treated PLGA scaffolds for cartilage tissue engineering. $J \mathrm{Appl}$ Biomater Funct Mater. 2013;11(1):e45-e52.

92. Foss C, Merzari E, Migliaresi C, et al. Silk fibroin/hyaluronic acid $3 \mathrm{D}$ matrices for cartilage tissue engineering. Biomacromolecules 2013;14(1):38-47.

93. Matsiko A, Levingstone TJ, O'Brien FJ, et al. Addition of hyaluronic acid improves cellular infiltration and promotes early-stage chondrogenesis in a collagen-based scaffold for cartilage tissue engineering. J Mech Behav Biomed Mater. 2012;11:41-52.

94. Schuurman W, Levett PA, Pot MW, et al. Gelatin-methacrylamide hydrogels as potential biomaterials for fabrication of tissue-engineered cartilage constructs. Macromol Biosci. 2013;13(5):551-561.

95. Deng J, She R, Huang W, et al. A silk fibroin/chitosan scaffold in combination with bone marrow-derived mesenchymal stem cells to repair cartilage defects in the rabbit knee. J Mater Sci Mater Med. 2013;24(8):2037-2046.

96. Whu SW, Hung $\mathrm{KC}$, Hsieh $\mathrm{KH}$, et al. In vitro and in vivo evaluation of chitosan-gelatin scaffolds for cartilage tissue engineering. Mater Sci Eng C Mater Biol Appl. 2013;33(5):2855-2863.

97. Yang Z, Wu Y, Li C, et al. Improved mesenchymal stem cells attachment and in vitro cartilage tissue formation on chitosan-modified poly(L-lactide-co-epsilon-caprolactone) scaffold. Tissue Eng Part A. 2012;18(3-4):242-251.

98. Zhang W, Chen J, Tao J, et al. The promotion of osteochondral repair by combined intra-articular injection of parathyroid hormone-related protein and implantation of a bi-layer collagen-silk scaffold. Biomaterials. 2013;34(25):6046-6057.

99. Vadala G, Mozetic P, Rainer A, et al. Bioactive electrospun scaffold for annulus fibrosus repair and regeneration. Eur Spine J. 2012;21(Suppl 1): S20-S26.

100. Dong S, Guo H, Zhang Y, et al. rFN/Cad-11-modified collagen type II biomimetic interface promotes the adhesion and chondrogenic differentiation of mesenchymal stem cells. Tissue Eng Part A. 2013;19(21-22):2464-2477.

101. Bunge RP, Puckett WR, Becerra JL, et al. Observations on the pathology of human spinal cord injury. A review and classification of 22 new cases with details from a case of chronic cord compression with extensive focal demyelination. Adv Neurol. 1993;59:75-89.

102. Schwab ME, Bartholdi D. Degeneration and regeneration of axons in the lesioned spinal cord. Physiol Rev. 1996;76(2):319-370.

103. Volpato FZ, Fuhrmann T, Migliaresi C, et al. Using extracellular matrix for regenerative medicine in the spinal cord. Biomaterials. 2013;34(21):4945-4955.
104. Shrestha B, Coykendall K, Li Y, et al. Repair of injured spinal cord using biomaterial scaffolds and stem cells. Stem Cell Res Ther. 2014;5(4):91.

105. Gros T, Sakamoto JS, Blesch A, et al. Regeneration of long-tract axons through sites of spinal cord injury using templated agarose scaffolds. Biomaterials. 2010;31(26):6719-6729.

106. Gao M, Lu P, Bednark B, et al. Templated agarose scaffolds for the support of motor axon regeneration into sites of complete spinal cord transection. Biomaterials. 2013;34(5):1529-1536.

107. Li X, Yang Z, Zhang A, et al. Repair of thoracic spinal cord injury by chitosan tube implantation in adult rats. Biomaterials. 2009;30(6):1121-1132.

108. Zeng X, Zeng YS, Ma YH, et al. Bone marrow mesenchymal stem cells in a three-dimensional gelatin sponge scaffold attenuate inflammation, promote angiogenesis, and reduce cavity formation in experimental spinal cord injury. Cell Transplant. 2011;20(11-12):1881-1899.

109. Kang KN, Lee JY, Kim da Y, et al. Regeneration of completely transected spinal cord using scaffold of poly(D, L-lactide-coglycolide)/small intestinal submucosa seeded with rat bone marrow stem cells. Tissue Eng Part A. 2011;17(17-18):2143-2152.

110. Hwang DH, Kim HM, Kang YM, et al. Combination of multifaceted strategies to maximize the therapeutic benefits of neural stem cell transplantation for spinal cord repair. Cell Transplant. 2011;20(9): 1361-1379

111. Sicari BM, Dearth CL, Badylak SF. Tissue engineering and regenerative medicine approaches to enhance the functional response to skeletal muscle injury. Anat Rec (Hoboken). 2014;297(1):51-64.

112. Peault B, Rudnicki M, Torrente Y, et al. Stem and progenitor cells in skeletal muscle development, maintenance, and therapy. Mol Ther. 2007;15(5):867-877.

113. Skuk D, Goulet M, Roy B, et al. Dystrophin expression in muscles of duchenne muscular dystrophy patients after high-density injections of normal myogenic cells. J Neuropathol Exp Neurol. 2006;65(4): 371-386

114. Thorrez L, Shansky J, Wang L, et al. Growth, differentiation, transplantation and survival of human skeletal myofibers on biodegradable scaffolds. Biomaterials. 2008;29(1):75-84.

115. Choi JS, Lee SJ, Christ GJ, et al. The influence of electrospun aligned poly(epsilon-caprolactone)/collagen nanofiber meshes on the formation of self-aligned skeletal muscle myotubes. Biomaterials. 2008;29(19):2899-2906.

116. Ma J, Holden K, Zhu J, et al. The application of three-dimensional collagen-scaffolds seeded with myoblasts to repair skeletal muscle defects. J Biomed Biotechnol. 2011;2011:812135.

117. Carnio S, Serena E, Rossi CA, et al. Three-dimensional porous scaffold allows long-term wild-type cell delivery in dystrophic muscle. JTissue Eng Regen Med. 2011;5(1):1-10.

118. Engler AJ, Griffin MA, Sen S, et al. Myotubes differentiate optimally on substrates with tissue-like stiffness: pathological implications for soft or stiff microenvironments. J Cell Biol. 2004;166(6):877-887.

119. Engler AJ, Sen S, Sweeney HL, et al. Matrix elasticity directs stem cell lineage specification. Cell. 2006;126(4):677-689.

120. Corona BT, Machingal MA, Criswell T, et al. Further development of a tissue engineered muscle repair construct in vitro for enhanced functional recovery following implantation in vivo in a murine model of volumetric muscle loss injury. Tissue Eng Part A. 2012;18 (11-12):1213-1228.

121. Machingal MA, Corona BT, Walters TJ, et al. A tissue-engineered muscle repair construct for functional restoration of an irrecoverable muscle injury in a murine model. Tissue Eng Part A. 2011;17 (17-18):2291-2303.

122. Balazs EA, Watson D, Duff IF, et al. Hyaluronic acid in synovial fluid. I. Molecular parameters of hyaluronic acid in normal and arthritis human fluids. Arthritis Rheum. 1967;10(4):357-376.

123. Fraser JRE, Kimpton WG, Pierscionek BK, et al. The kinetics of hyaluronan in normal and acutely inflamed synovial joints: observations with experimental arthritis in sheep. Semin Arthritis Rheum. 1993;22(6 Suppl 1):9-17. 
124. McArthur BA, Dy CJ, Fabricant PD, et al. Long term safety, efficacy, and patient acceptability of hyaluronic acid injection in patients with painful osteoarthritis of the knee. Patient Prefer Adherence. 2012;6:905-910.

125. Moreland LW. Intra-articular hyaluronan (hyaluronic acid) and hylans for the treatment of osteoarthritis: mechanisms of action. Arthritis Res Ther. 2003;5(2):54-67.

126. Greenwald RA. Oxygen radicals, inflammation, and arthritis: pathophysiological considerations and implications for treatment. Semin Arthritis Rheum. 1991;20(4):219-240.

127. Evaniew N, Hanson B, Winemaker M. Viscosupplementation for knee osteoarthritis: current evidence and recommendations. J Long Term Eff Med Implants. 2013;23(2-3):151-159.

128. Axe JM, Snyder-Mackler L, Axe MJ. The role of viscosupplementation. Sports Med Arthrosc. 2013;21(1):18-22.

129. Brockmeier SF, Shaffer BS. Viscosupplementation therapy for osteoarthritis. Sports Med Arthrosc. 2006;14(3):155-162.

130. Bellamy N, Campbell J, Robinson V, et al. Viscosupplementation for the treatment of osteoarthritis of the knee. Cochrane Database Syst Rev. 2006;(2):CD005321.

131. Campbell J, Bellamy N, Gee T. Differences between systematic reviews/ meta-analyses of hyaluronic acid/hyaluronan/hylan in osteoarthritis of the knee. Osteoarthritis Cartilage. 2007;15(12):1424-1436.

132. Rutjes AW, Juni P, da Costa BR, et al. Viscosupplementation for osteoarthritis of the knee: a systematic review and meta-analysis. Ann Intern Med. 2012;157(3):180-191.

133. McAlindon TE, Bannuru RR, Sullivan MC, et al. OARSI guidelines for the non-surgical management of knee osteoarthritis. Osteoarthritis Cartilage. 2014;22(3):363-388.

134. Zhang W, Moskowitz RW, Nuki G, et al. OARSI recommendations for the management of hip and knee osteoarthritis, part II: OARSI evidence-based, expert consensus guidelines. Osteoarthritis Cartilage. 2008;16(2):137-162

135. Zhang W, Nuki G, Moskowitz RW, et al. OARSI recommendations for the management of hip and knee osteoarthritis: part III: changes in evidence following systematic cumulative update of research published through January 2009. Osteoarthritis Cartilage. 2010;18(4):476-499.

136. Richmond J, Hunter D, Irrgang J, et al. Treatment of osteoarthritis of the knee (nonarthroplasty). J Am Acad Orthop Surg. 2009;17(9): 591-600.

137. AAOS. Treatment of Osteoarthritis of the Knee. 2nd ed. Rosemont, IL: AAOS; 2013.

138. Burdick JA, Prestwich GD. Hyaluronic acid hydrogels for biomedical applications. Adv Mater. 2011;23(12):H41-H56.

139. Prestwich GD. Hyaluronic acid-based clinical biomaterials derived for cell and molecule delivery in regenerative medicine. J Control Release. 2011;155(2):193-199.

140. Park H, Choi B, Hu J, et al. Injectable chitosan hyaluronic acid hydrogels for cartilage tissue engineering. Acta Biomater. 2013;9(1): 4779-4786.

141. Bhakta G, Rai B, Lim ZX, et al. Hyaluronic acid-based hydrogels functionalized with heparin that support controlled release of bioactive BMP-2. Biomaterials. 2012;33(26):6113-6122.

142. Erickson IE, Kestle SR, Zellars KH, et al. High mesenchymal stem cell seeding densities in hyaluronic acid hydrogels produce engineered cartilage with native tissue properties. Acta Biomater. 2012;8(8): 3027-3034.

143. Toh WS, Lim TC, Kurisawa M, et al. Modulation of mesenchymal stem cell chondrogenesis in a tunable hyaluronic acid hydrogel microenvironment. Biomaterials. 2012;33(15):3835-3845.

144. Dalton PD, Flynn L, Shoichet MS. Manufacture of poly(2-hydroxyethyl methacrylate-co-methyl methacrylate) hydrogel tubes for use as nerve guidance channels. Biomaterials. 2002;23(18):3843-3851.

145. Ozawa $\mathrm{H}$, Matsumoto $\mathrm{T}$, Ohashi $\mathrm{T}$, et al. Comparison of spinal cord gray matter and white matter softness: measurement by pipette aspiration method. J Neurosurg. 2001;95(2 Suppl):221-224.
146. Tsai EC, Dalton PD, Shoichet MS, et al. Synthetic hydrogel guidance channels facilitate regeneration of adult rat brainstem motor axons after complete spinal cord transection. J Neurotrauma. 2004;21(6):789-804.

147. Nomura H, Katayama Y, Shoichet MS, et al. Complete spinal cord transection treated by implantation of a reinforced synthetic hydrogel channel results in syringomyelia and caudal migration of the rostral stump. Neurosurgery. 2006;59(1):183-192; discussion 183-192.

148. King VR, Alovskaya A, Wei DY, et al. The use of injectable forms of fibrin and fibronectin to support axonal ingrowth after spinal cord injury. Biomaterials. 2010;31(15):4447-4456.

149. Wei YT, He Y, Xu CL, et al. Hyaluronic acid hydrogel modified with nogo-66 receptor antibody and poly-L-lysine to promote axon regrowth after spinal cord injury. J Biomed Mater Res B Appl Biomater. 2010;95(1):110-117.

150. Park J, Lim E, Back S, et al. Nerve regeneration following spinal cord injury using matrix metalloproteinase-sensitive, hyaluronic acid-based biomimetic hydrogel scaffold containing brain-derived neurotrophic factor. J Biomed Mater Res A. 2010;93(3):1091-1099.

151. Mothe AJ, Tam RY, Zahir T, et al. Repair of the injured spinal cord by transplantation of neural stem cells in a hyaluronan-based hydrogel. Biomaterials. 2013;34(15):3775-3783.

152. Hejcl A, Sedy J, Kapcalova M, et al. HPMA-RGD hydrogels seeded with mesenchymal stem cells improve functional outcome in chronic spinal cord injury. Stem Cells Dev. 2010;19(10):1535-1546.

153. Zhang BG, Myers DE, Wallace GG, et al. Bioactive coatings for orthopaedic implants-recent trends in development of implant coatings. Int J Mol Sci. 2014;15(7):11878-11921.

154. Goodman SB, Yao Z, Keeney M, et al. The future of biologic coatings for orthopaedic implants. Biomaterials. 2013;34(13):3174-3183.

155. Wang J, Guo J, Liu J, et al. BMP-functionalised coatings to promote osteogenesis for orthopaedic implants. Int J Mol Sci. 2014;15(6):10150-10168.

156. Kim M, Jung WK, Kim G. Bio-composites composed of a solid free-form fabricated polycaprolactone and alginate-releasing bone morphogenic protein and bone formation peptide for bone tissue regeneration. Bioprocess Biosyst Eng. 2013;36(11):1725-1734.

157. Poth N, Seiffart V, Gross G, et al. Biodegradable chitosan nanoparticle coatings on titanium for the delivery of BMP-2. Biomolecules. 2015;5(1):3-19.

158. Gao Y, Zou S, Liu X, et al. The effect of surface immobilized bisphosphonates on the fixation of hydroxyapatite-coated titanium implants in ovariectomized rats. Biomaterials. 2009;30(9):1790-1796.

159. Kajiwara H, Yamaza T, Yoshinari M, et al. The bisphosphonate pamidronate on the surface of titanium stimulates bone formation around tibial implants in rats. Biomaterials. 2005;26(6):581-587.

160. Yoshinari M, Oda $\mathrm{Y}$, Inoue $\mathrm{T}$, et al. Bone response to calcium phosphate-coated and bisphosphonate-immobilized titanium implants. Biomaterials. 2002;23(14):2879-2885.

161. Victor SP, Muthu J. Bioactive, mechanically favorable, and biodegradable copolymer nanocomposites for orthopedic applications. Mater Sci Eng C Mater Biol Appl. 2014;39:150-160.

162. Surmenev RA, Surmeneva MA, Ivanova AA. Significance of calcium phosphate coatings for the enhancement of new bone osteogenesis a review. Acta Biomater. 2014;10(2):557-579.

163. Yan J, Sun JF, Chu PK, et al. Bone integration capability of a series of strontium-containing hydroxyapatite coatings formed by micro-arc oxidation. J Biomed Mater Res A. 2013;101(9):2465-2480.

164. Gomes PS, Botelho C, Lopes MA, et al. Evaluation of human osteoblastic cell response to plasma-sprayed silicon-substituted hydroxyapatite coatings over titanium substrates. J Biomed Mater Res B Appl Biomater. 2010;94(2):337-346.

165. Motoc MM, Axente E, Popescu C, et al. Active protein and calcium hydroxyapatite bilayers grown by laser techniques for therapeutic applications. J Biomed Mater Res A. 2013;101(9):2706-2711. 
166. Roy M, Fielding GA, Beyenal H, et al. Mechanical, in vitro antimicrobial, and biological properties of plasma-sprayed silver-doped hydroxyapatite coating. ACS Appl Mater Interfaces. 2012;4(3):1341-1349.

167. Campoccia D, Montanaro L, Arciola CR. A review of the biomaterials technologies for infection-resistant surfaces. Biomaterials. 2013;34(34):8533-8554.

168. Kargupta R, Bok S, Darr CM, et al. Coatings and surface modifications imparting antimicrobial activity to orthopedic implants. Wiley Interdiscip Rev Nanomed Nanobiotechnol. 2014;6(5):475-495.

169. Zhang L, Yan J, Yin Z, et al. Electrospun vancomycin-loaded coating on titanium implants for the prevention of implant-associated infections. Int J Nanomed. 2014;9:3027-3036.

170. Ordikhani F, Tamjid E, Simchi A. Characterization and antibacterial performance of electrodeposited chitosan-vancomycin composite coatings for prevention of implant-associated infections. Mater Sci Eng C Mater Biol Appl. 2014;41:240-248.

171. Jones JR. Review of bioactive glass: from Hench to hybrids. Acta Biomater. 2013;9(1):4457-4486.

172. Hench LL. The story of bioglass. J Mater Sci Mater Med. 2006;17(11):967-978.

173. Chaudhari A, Braem A, Vleugels J, et al. Bone tissue response to porous and functionalized titanium and silica based coatings. PLoS One. 2011;6(9):e24186.

174. Newman SD, Lotfibakhshaiesh N, O'Donnell M, et al. Enhanced osseous implant fixation with strontium-substituted bioactive glass coating. Tissue Eng Part A. 2014;20(13-14):1850-1857.

175. Arts MP, Wolfs JF, Corbin TP. The CASCADE trial: effectiveness of ceramic versus PEEK cages for anterior cervical discectomy with interbody fusion; protocol of a blinded randomized controlled trial. BMC Musculoskelet Disord. 2013;14:244.

176. Anderson MC, Olsen R. Bone ingrowth into porous silicon nitride. $J$ Biomed Mater Res A. 2010;92(4):1598-1605.

177. Amedica Corporation. Amedica's Spinal Interbody Spacers with Porous Silicon Nitride Center Provide Equivalent Fusion to PEEK Spacers with Bone Autograft. Salt Lake City, UT: Amedica Corporation; 2015. Available from: http://investors.amedica.com/releasedetail. cfm?releaseid=889382. Accessed July 27, 2015.

178. Webster TJ, Patel AA, Rahaman MN, et al. Anti-infective and osteointegration properties of silicon nitride, poly(ether ether ketone), and titanium implants. Acta Biomater. 2012;8(12):4447-4454.

179. Kato S, Murakami H, Demura S, et al. Vertebral osteomyelitis caused by mycobacterium abscessus surgically treated using antibacterial iodine-supported instrumentation. Case Rep Orthop. 2014;2014: 197061.

180. Shirai T, Shimizu T, Ohtani K, et al. Antibacterial iodine-supported titanium implants. Acta Biomater. 2011;7(4):1928-1933.

181. Demura S, Murakami H, Shirai T, et al. Surgical treatment for pyogenic vertebral osteomyelitis using iodine-supported spinal instruments: initial case series of 14 patients. Eur J Clin Microbiol Infect Dis 2015;34(2):261-266.

182. Shirai T, Tsuchiya H, Nishida H, et al. Antimicrobial megaprostheses supported with iodine. J Biomater Appl. 2014;29(4):617-623.

183. Tsuchiya H, Shirai $\mathrm{T}$, Nishida $\mathrm{H}$, et al. Innovative antimicrobial coating of titanium implants with iodine. J Orthop Sci. 2012;17(5):595-604.

184. Zwingenberger S, Nich C, Valladares RD, et al. Recommendations and considerations for the use of biologics in orthopedic surgery. BioDrugs. 2012;26(4):245-256.

185. Froum SJ, Weinberg MA, Tarnow D. Comparison of bioactive glass synthetic bone graft particles and open debridement in the treatment of human periodontal defects. A clinical study. J Periodontol. 1998;69(6):698-709.

186. Hoppe A, Mourino V, Boccaccini A. Therapeutic inorganic ions in bioactive glasses to enchance bone formation and beyond. Biomater Sci. 2013;1:254-256.
187. Meunier PJ, Roux C, Seeman E, et al. The effects of strontium ranelate on the risk of vertebral fracture in women with postmenopausal osteoporosis. N Engl J Med. 2004;350(5):459-468.

188. Boyd D, Carroll G, Towler MR, et al. Preliminary investigation of novel bone graft substitutes based on strontium-calcium-zinc-silicate glasses. J Mater Sci Mater Med. 2009;20(1):413-420.

189. Bernhardt A, Dittrich R, Lode A, et al. Nanocrystalline spherical hydroxyapatite granules for bone repair: in vitro evaluation with osteoblast-like cells and osteoclasts. J Mater Sci Mater Med. 2013;24(7):1755-1766.

190. Coathup MJ, Cai Q, Campion C, et al. The effect of particle size on the osteointegration of injectable silicate-substituted calcium phosphate bone substitute materials. J Biomed Mater Res B Appl Biomater. 2013;101(6):902-910.

191. Dobelin N, Luginbuhl R, Bohner M. Synthetic calcium phosphate ceramics for treatment of bone fractures. Chimia (Aarau). 2010;64(10) 723-729.

192. Lyons FG, Gleeson JP, Partap S, et al. Novel microhydroxyapatite particles in a collagen scaffold: a bioactive bone void filler? Clin Orthop Relat Res. 2014;472(4):1318-1328.

193. Campana V, Milano G, Pagano E, et al. Bone substitutes in orthopaedic surgery: from basic science to clinical practice. J Mater Sci Mater Med. 2014;25(10):2445-2461.

194. Kumar CY, K B N, Menon J, et al. Calcium sulfate as bone graft substitute in the treatment of osseous bone defects, a prospective study. J Clin Diagn Res. 2013;7(12):2926-2928.

195. Nilsson M, Zheng MH, Tagil M. The composite of hydroxyapatite and calcium sulphate: a review of preclinical evaluation and clinical applications. Expert Rev Med Devices. 2013;10(5):675-684.

196. Abramo A, Geijer M, Kopylov P, et al. Osteotomy of distal radius fracture malunion using a fast remodeling bone substitute consisting of calcium sulphate and calcium phosphate. J Biomed Mater Res B Appl Biomater. 2010;92(1):281-286.

197. Schindler OS, Cannon SR, Briggs TW, et al. Use of a novel bone graft substitute in peri-articular bone tumours of the knee. Knee. 2007;14(6):458-464.

198. Walschot LH, Aquarius R, Schreurs BW, et al. Osteoconduction of impacted porous titanium particles with a calcium-phosphate coating is comparable to osteoconduction of impacted allograft bone particles: in vivo study in a nonloaded goat model. J Biomed Mater Res B Appl Biomater. 2012;100(6):1483-1489.

199. Walschot LH, Aquarius R, Verdonschot N, et al. Porous titanium particles for acetabular reconstruction in total hip replacement show extensive bony armoring after 15 weeks. Acta Orthop. 2014;85(6):600-608

200. Castilho M, Moseke C, Ewald A, et al. Direct 3D powder printing of biphasic calcium phosphate scaffolds for substitution of complex bone defects. Biofabrication. 2014;6(1):015006.

201. Gibbs DM, Vaezi M, Yang S, et al. Hope versus hype: what can additive manufacturing realistically offer trauma and orthopedic surgery? Regen Med. 2014;9(4):535-549.

202. Herbert N, Simpson D, Spence WD, et al. A preliminary investigation into the development of 3-D printing of prosthetic sockets. J Rehabil Res Dev. 2005;42(2):141-146.

203. Zopf DA, Hollister SJ, Nelson ME, et al. Bioresorbable airway splint created with a three-dimensional printer. $N$ Engl J Med. 2013;368(21):2043-2045.

204. Weisman JA, Nicholson JC, Tappa K, et al. Antibiotic and chemotherapeutic enhanced three-dimensional printer filaments and constructs for biomedical applications. Int J Nanomed. 2015;10:357-370.

205. Robbins MM, Vaccaro AR, Madigan L. The use of variables affecting convection implants in spine surgery. Neurosurg Focus. 2004;16(3):E1

206. Collins MN, Birkinshaw C. Hyaluronic acid based scaffolds for tissue engineering - a review. Carbohydrate Polym. 2013;92(2) $1262-1279$. 


\section{Publish your work in this journal}

Orthopedic Research and Reviews is an international, peer-reviewed, open access journal focusing on the patho-physiology of the musculoskeletal system, trauma, surgery and other corrective interventions to restore mobility and function. Advances in new technologies, materials, techniques and pharmacological agents are particularly welcome. The journal welcomes

original research, clinical studies, reviews \& evaluations, expert opinion and commentary, case reports and extended reports. The manuscript management system is completely online and includes a very quick and fair peer-review system, which is all easy to use. Visit http://www.dovepress. com/testimonials.php to read real quotes from published authors.

Submit your manuscript here: http://www.dovepress.com/orthopedic-research-and-reviews-journal 